OECD Science, Technology and Industry Working Papers 2003/06

\title{
Measuring Investment in Software
}

\author{
Nadim Ahmad
}


Organisation de Coopération et de Développement Economiques

DIRECTORATE FOR SCIENCE, TECHNOLOGY AND INDUSTRY

\section{MEASURING INVESTMENT IN SOFTWARE}

STI WORKING PAPER 2003/6

Statistical Analysis of Science, Technology and Industry

Nadim Ahmad 


\section{STI Working Paper Series}

The Working Paper series of the OECD Directorate for Science, Technology and Industry is designed to make available to a wider readership selected studies prepared by staff in the Directorate or by outside consultants working on OECD projects. The papers included in the series cover a broad range of issues, of both a technical and policy-analytical nature, in the areas of work of the DSTI. The Working Papers are generally available only in their original language - English or French - with a summary in the other.

Comment on the papers is invited, and should be sent to the Directorate for Science, Technology and Industry, OECD, 2 rue André-Pascal, 75775 Paris Cedex 16, France.

The opinions expressed in these papers are the sole responsibility of the author(s) and do not necessarily reflect those of the OECD or of the governments of its member countries.

\section{http://www.oecd.org/sti/working-papers}




\title{
MEASURING INVESTMENT IN SOFTWARE
}

\author{
Nadim Ahmad \\ Directorate for Science, Technology and Industry, \\ Economic Analysis Division \\ OECD
}

\begin{abstract}
The latest system of national accounts (SNA93) recommended that purchases of software (and any own-account production) should be capitalised as long as the acquisition satisfied conventional asset requirements. This change added about $1 \%$ to GDP in most OECD economies in the mid-1990s. However, the range of the revision has been significantly different across countries, leading many observers to question the comparability of these statistics. An OECD task force set up in October 2001 confirmed that differences in estimation procedures contributed significantly to the differences in software capitalisation rates, and a set of recommendations describing a harmonised method for estimating software were formulated. Most of these recommendations were approved at the OECD 2002 National Accounts Expert meeting. This paper reviews the recommendations in its annexes, giving more expansive explanations in some areas, and provides estimates of changes to GDP levels and growth that might be expected if the OECD recommendations were applied. Estimates of changes are also presented using an alternative harmonised method. Whichever harmonised method is applied, the impact on GDP levels is likely to be significant, and in some countries about $1 \%$.
\end{abstract}




\title{
LA MESURE DE L'INVESTISSEMENT DANS LES LOGICIELS
}

\author{
Nadim Ahmad \\ Direction de la science, de la technologie et de l'industrie \\ Division des analyses économiques et des statistiques \\ OCDE
}

\begin{abstract}
Résumé
La plus récente des éditions du Système de comptabilité nationale (SCN 93) a recommandé de considérer les achats de logiciels (et toute production pour compte propre) comme un investissement pour autant que l'acquisition satisfasse aux critères applicables aux actifs traditionnels. Cette modification devait se traduire par une progression d'environ $1 \%$ du PIB dans la plupart des économies de l'OCDE vers le milieu des années 90 . Toutefois la portée de cette révision a été sensiblement différente suivant les pays, ce qui a conduit de nombreux observateurs à s'interroger sur la comparabilité de ces statistiques. Un groupe spécial de l'OCDE créé en octobre 2001 a confirmé que des différences dans les procédures d'estimation contribuaient fortement aux écarts dans les taux de capitalisation des logiciels, et une série de recommandations décrivant une méthodologie unifiée pour l'estimation du logiciel a été formulée. La plupart de ces recommandations ont été approuvées lors de la Réunion de l'OCDE d'experts en comptabilité nationale en 2002. Le présent document passe en revue ces recommandations dans ses annexes, en proposant des explications plus détaillées sur certains aspects, et il fournit des estimations des changements dans les niveaux du PIB et la croissance qui pourraient être escomptés si les recommandations de l'OCDE étaient mises en oeuvre. Des estimations des changements sont également présentées selon une autre méthode harmonisée. Quelle que soit la méthode harmonisée utilisée, l'incidence sur les niveaux de PIB devrait être significative dans certains pays (environ 1\%).
\end{abstract}




\section{TABLE OF CONTENTS}

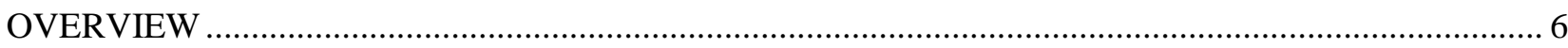

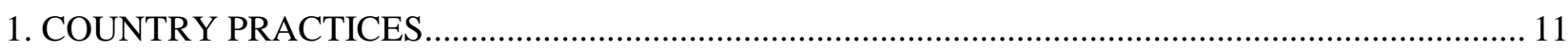

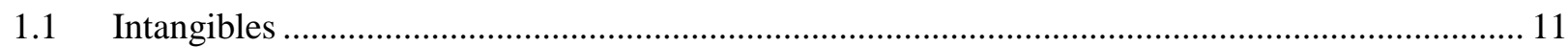

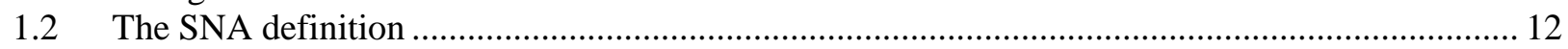

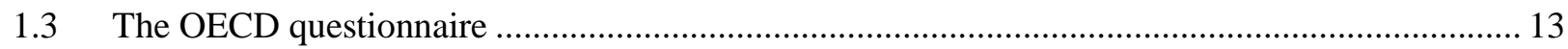

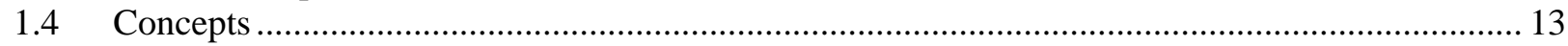

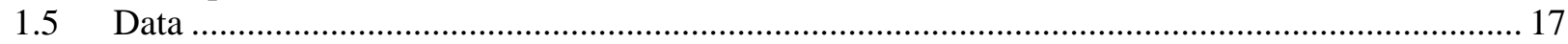

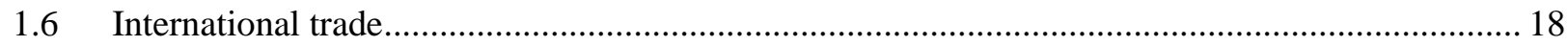

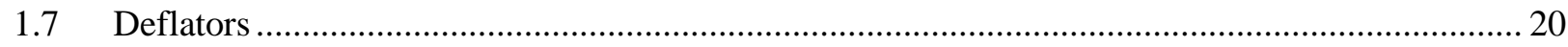

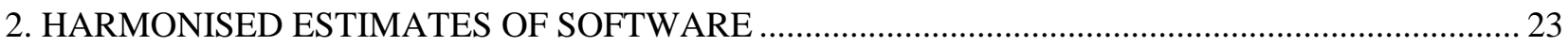

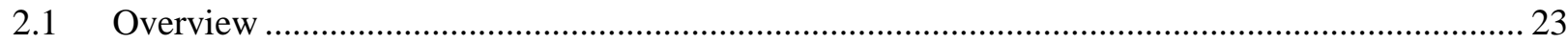

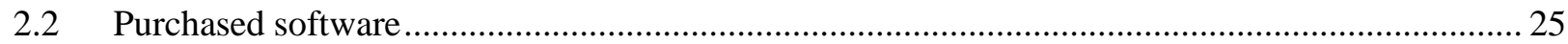

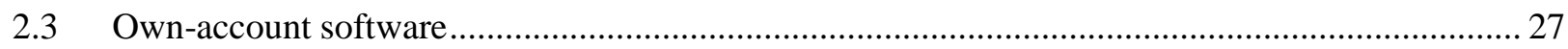

2.4 Total investment: harmonised using Task Force recommendations........................................... 31

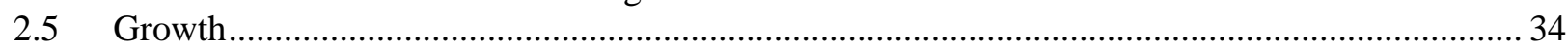

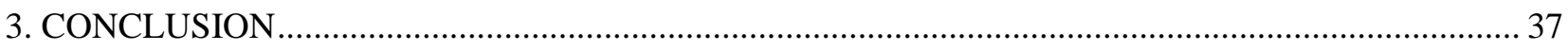

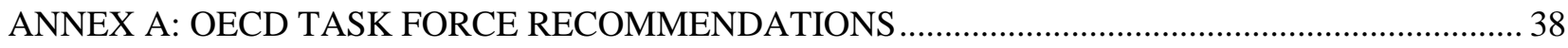

A1: SOFTWARE INVESTMENT IN THE SNA AND BUSINESS ACCOUNTS ..................................... 39

A.1.1 What is investment? (gross fixed capital formation) ................................................................. 39

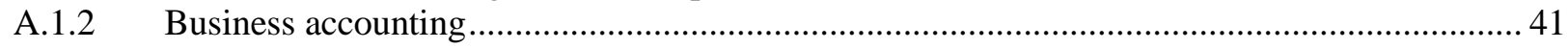

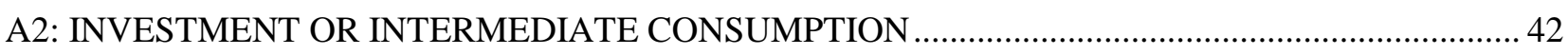

A.2.1 Software transactions - investment or intermediate ................................................ 42

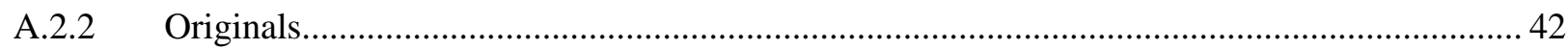

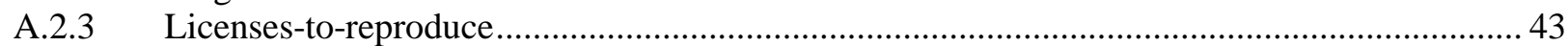

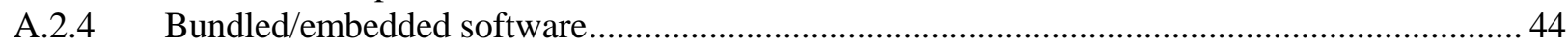

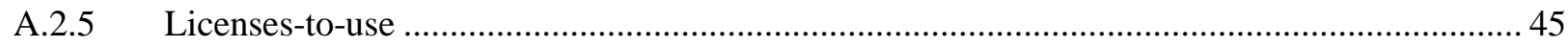

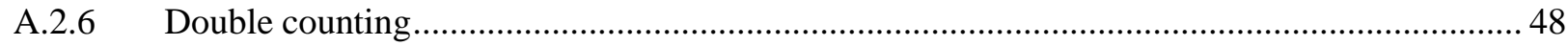

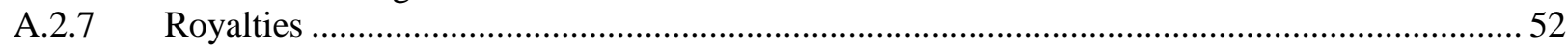

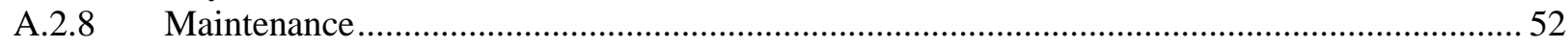

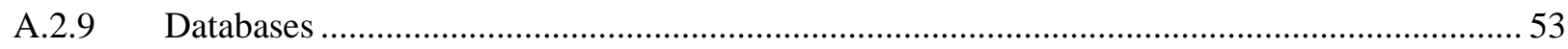

A.3: ESTIMATING SOFTWARE INVESTMENT IN PRACTICE - THE SUPPLY METHOD .............. 59

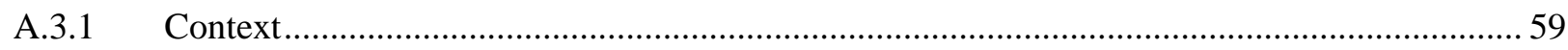

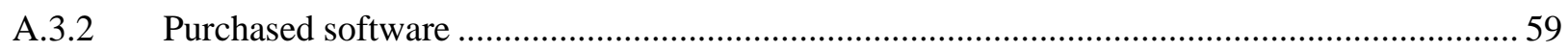

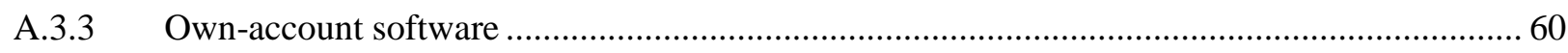

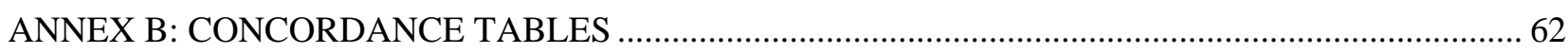

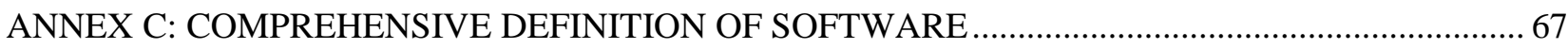




\section{OVERVIEW}

1. A change was made in the latest system of national accounts (SNA93) that recommended the capitalisation of software. This recognised the "asset" characteristics of software, its increasingly important contribution to economic growth and productivity, and brought the treatment of software purchased separately into line with software purchased as a bundle, which has always been capitalised. However this has caused deterioration in the international comparability of economic statistics. ${ }^{1}$

Figure 1. Total investment in software, percentage of GDP

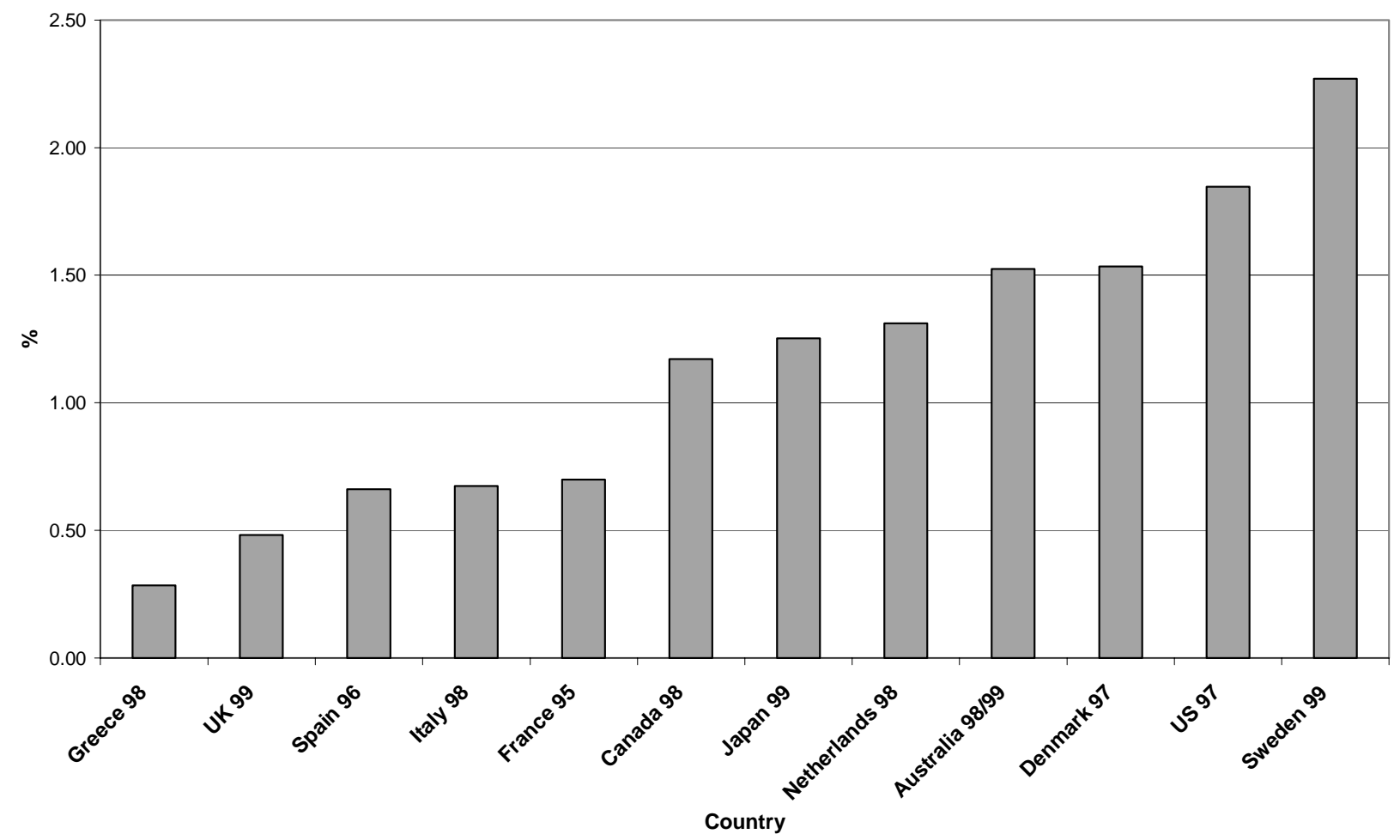

Source: OECD questionnaire on software.

2. On average, the change has increased GDP by over $1 \%$ in OECD economies but the variability is significant (see Figure 1) and the difficulty to explain differences in an economically meaningful way has led many observers to question the role measurement plays. For example, according to official statistics,

1. This is not the only area of the national accounts where differences exist. A forthcoming OECD paper, "Comparing Growth and Productivity Performance in the OECD Area - The Role of Measurement", describes these other areas and provides qualitative assessments on the impact of these differences on the comparability of growth for OECD economies. 
Denmark has three times the software investment levels of the United Kingdom (as a percentage of GDP ${ }^{2}$ ) but has a software producing industry only two-thirds of the size (as a percentage of GDP).

3. Two distinct methods exist for estimating investment in software. The first is based on how businesses record investment in practice, using a conventional survey-based approach (known as a "demand" approach). The second is to measure the total supply of computer services into an economy and estimate expenditure on software with asset characteristics (the "supply" approach). Some statistical offices use the latter approach since demand-based methods are based on businesses' own valuations, which tend to be very prudent (often zero) and are not always consistent with the SNA definition of software.

4. Central to the issue of measurement therefore is how capital expenditure on computer services (software) is delineated from intermediate consumption in computer services when using a supply approach. In other words, the ratio of capitalised software to total expenditure (by businesses and government) on computer services (the investment ratio) is a measure of the propensity of any country's statistical office to capitalise software. "Computer services" is usually defined within international and national product classification systems, for example, CPA72, for the European product classification system (or US SIC 73.7 for the US industrial classification system, or NAICS 541511, 511210, 541512, $518210,541513,518210,541512,541519$, the latest US classification system). It covers a fairly heterogeneous range of services, some with asset characteristics, e.g. customised software services, and some without, e.g. hardware consultancy. A priori one would expect the relative size of these services to total computer services to be fairly similar across economies, and so, by extension, if countries applied the same criteria to determine when to capitalise expenditure, one would expect investment ratios to be fairly similar too, and so a comparison of these ratios provides an insight into the scale of measurement differences across countries. Figure 2, below, showing the investment ratio for purchased software, confirms that the range is substantial, ${ }^{3}$ suggesting that measurement, rather than economic, factors lie behind the differences in software investment levels seen across countries.

2. Source for GDP: OECD National Accounts database.

3. Part of the reason for differences in ratios is that definitions for computer services are not exactly equivalent for all countries, although this cannot explain the differences for EU countries since the definition used within the EU is exactly the same. It is interesting to note that at the more detailed level, (four and six-digit product classification) differences are larger. For example, for a given expense of 100 on similar (detailed) types of software services, the United States will capitalise 100 whilst France will capitalise only 50. 
Figure 2. Investment ratios for purchased software

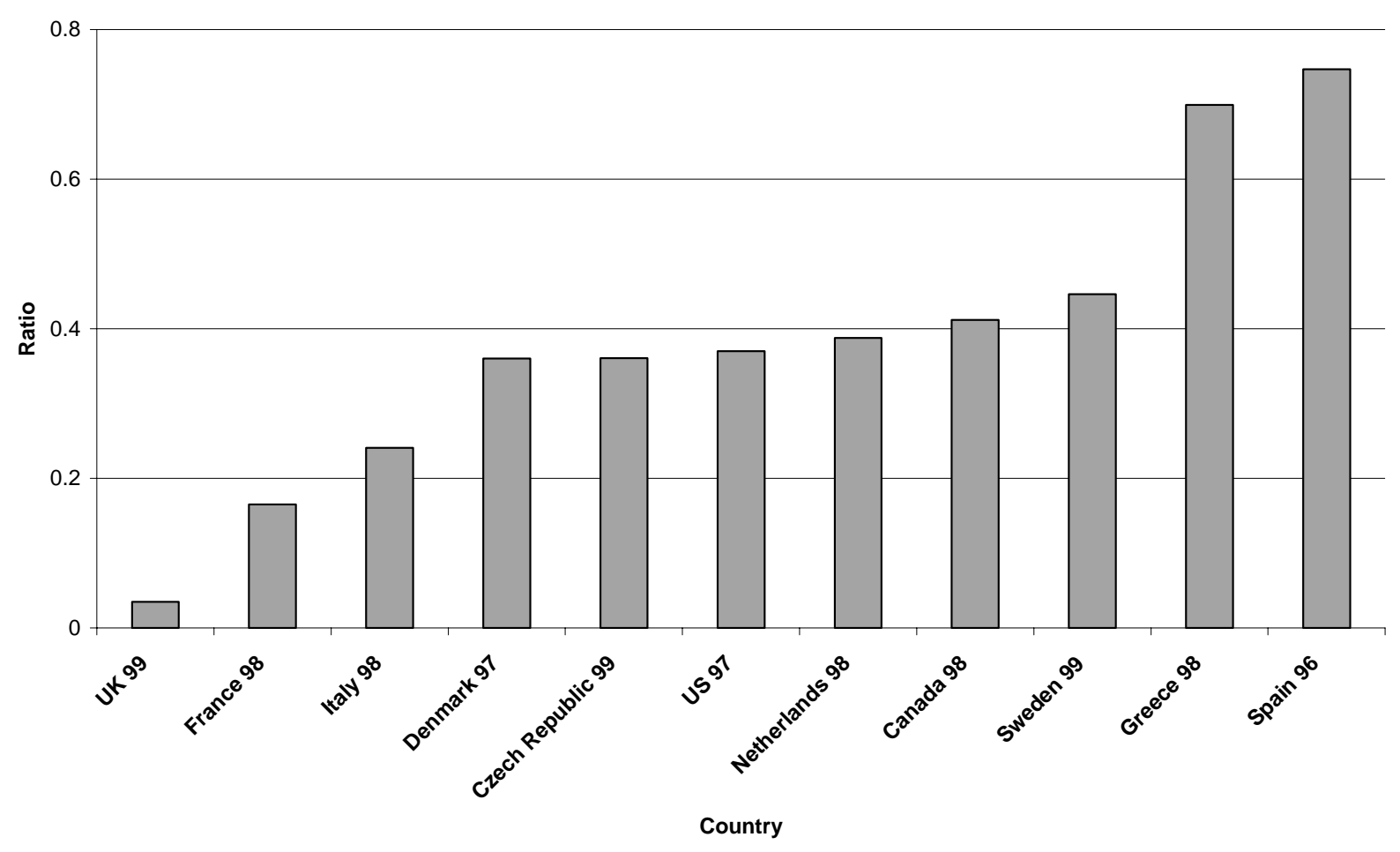

Source: OECD questionnaire on software.

5. To address these measurement issues, and improve international comparability, a joint OECD-Eurostat Task Force was set up in October 2001. A final report of the OECD Task Force was presented at the National Accounts Experts October 2002 meeting in Paris. The report is available at http://www.oecd.org/doc/M00034000/M00034026.doc. Most of the recommendations in the report were agreed unanimously. However, one issue, concerning the treatment of software reproductions, remains contentious $^{4}$ (see sections A2.5, 6 in Annex A). This paper presents some background into current country differences together with illustrative estimates based on the Task Force recommendations. Annex A of the paper revisits the recommendations made by the Software Task Force, providing more detail in some areas, in particular the treatment of software reproductions.

6. The paper shows that harmonising software measurement methods, using the Task Force recommendations, could lead to significant revisions to the national accounts of some countries $(+/-1 \%$ of current price GDP levels and up to $0.25 \%$ a year on growth in some cases. However, from the outset it is important to recognise that harmonisation will be best achieved by national statistical offices (NSOs) and that the alternative estimates presented here for illustration should be considered as approximations, since they are based on more limited data sources than available in NSOs.

4. See Robin Lynch, "Accounting for Software Licenses" (Room Document 8, OECD National Accounts Expert Meeting, October 2002) (http://www.oecd.org/doc/M00034000/M00034502.doc) and Nadim Ahmad, "Accounting for Software Licenses" (Room Document 12, OECD National Accounts Expert Meeting, October 2002) (http://www.oecd.org/doc/M00034000/M00034766.doc). 
7. This paper is set out in two main sections, with three annexes:

- Country practices: Providing an overview of the software measurement problem and the causes of mismeasurement together with a description of the estimation methods used across countries.

- Harmonised estimates for software: Applying the recommendations set out in the Software Task Force report (Annex A), harmonised estimates for software investment and GDP are presented. The OECD report concludes that, under most circumstances, software copies are assets. However, this debate continues so estimates are also presented on the basis that reproductions are not capitalised (using the UK investment ratio as a benchmark). Figure 3 below shows the potential impact on GDP using two scenarios, assuming no other offsetting changes. ${ }^{5}$ The first shows the expected change to GDP assuming an investment ratio for purchased software of 0.4 (the average ratio across countries), which would imply significant changes to French and UK data. The second uses an investment ratio of 0.04 (using the UK ratio as a benchmark). On this basis GDP levels would decrease by about $1 \%$ in many countries.

Figure 3. Estimated impact on $\mathrm{GDP}^{5}$ (percentage) using different assumptions for investment ratios for purchased software

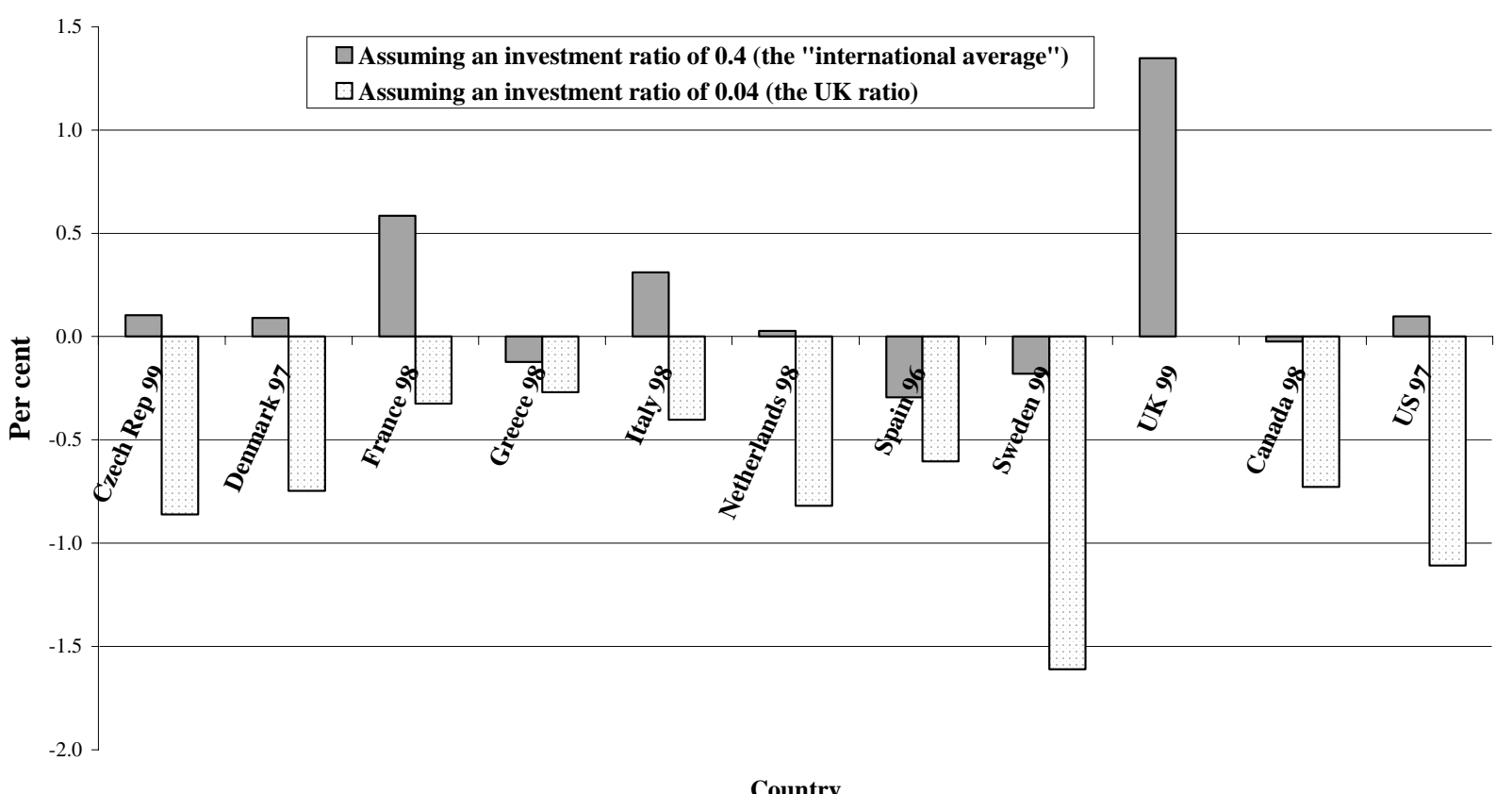

Source: OECD questionnaire on software (with assumptions for investment ratios). GDP: OECD National Accounts database.

5. The analysis shown in the paper assumes that any expenditure re-allocated from intermediate consumption to gross fixed capital formation has a full impact on GDP and investment. In practice, however, this may not be the case. In some countries total official levels of investment are considered to be robust, but the allocation of investment to specific asset categories, such as software, less so. In this regard an increase in software capitalisation may be made at the expense of reductions in the capitalisation of other products, leaving a net zero effect on overall GDP. 
- Annex A: Reviews the SNA rules for investment more generally, together with a review of business accounting recommendations for software capitalisation and what businesses do in practice. This is followed by a conceptual exposition that provides a theoretical framework for recording common and important software transactions in the national accounts, consistent with the OECD Task Force recommendations. Finally the OECD recommended procedure for using the supply method is described.

- Annex B: Describes relationships between classification systems and software transactions.

- Annex $C$ : Provides a comprehensive definition of software. 


\section{COUNTRY PRACTICES}

\subsection{Intangibles}

1.1.1 Despite its intangible nature, the rationale for capitalising software is firmly based. Like tangible assets, software delivers a stream of capital services. Indeed, the importance of these capital services on output and productivity has been well documented. However, transactions and production of tangible products are relatively easy to measure, since they have readily identifiable physical characteristics, conventional production processes, transparent service lives, and conventional markets but intangible products, in particular software, do not obviously share these characteristics, for example:

- The markets for software are unconventional and complicated. Software is usually sold with a number of conditions attached designed to deter unauthorised reproductions. These usually state that ownership of the software code remains the property of the software producing company. Whilst it is clear that this means that the software "original" remains the property of the software producing company, it is not clear whether this also applies to the reproduction, for national accounts purposes. As will be demonstrated, this paper and the OECD Task Force recommendations conclude that, for the national accounts, the conditions referring to ownership apply to the "original" and that users of software reproductions are the owners of the reproductions.

- Once a software original ${ }^{6}$ has been produced, copies can be reproduced at minimal cost, and conditions are often included that restrict the subsequent use or resale of the copy.

- The service life of software is difficult to measure. Software does not age like tangible products, which tend to become less efficient as a result of conventional "wear and tear".

- Like tangible products, reproduced software is often purchased using license arrangements. Unlike tangible products, however, when the license is terminated or comes to an end, the reproduced software ceases to exist and is not returned to the software company.

- Finally, it is not clear what the physical characteristics of reproduced software are. Do software copies actually exist or are they merely licenses/contracts that permit the use of, or access to, a software original?

1.1.2 These characteristics complicate software capitalisation but they do not invalidate it (see Annex A). The key problem for national accounts however is how to interpret these characteristics, and for international comparability, how to interpret them in a consistent way.

6. See Annex C for a comprehensive definition of software originals, and software in general. 


\subsection{The SNA definition}

\subsubsection{Paragraphs 10.92 and 10.93 of the SNA describe software as:}

Computer software that an enterprise expects to use in production for more than one year is treated as an intangible fixed asset. Such software may be purchased on the market or produced for own use. Acquisitions of such software are therefore treated as gross fixed capital formation. Software purchased on the market is valued at purchasers' prices, while software developed in-house is valued at its estimated basic price, or at its costs of production if it is not possible to estimate the basic price. Gross fixed capital formation in software also includes the purchase or development of large databases that the enterprise expects to use in production over a period of time of more than one year. These databases are valued in the same way as software.

1.2.2 A common interpretation of this is that software can be defined as follows:

- Pre-packaged or reproduced software.

- Own account software - software produced in-house, not destined for final sale. This can include the production of any software "original" intended for subsequent re-production.

- Customised software - this refers, in the main, to made-to-order software systems.

1.2.3 While this is slightly more meaningful than the SNA description, it is not particularly prescriptive, and this has led to problems with international comparability. Neither definition, for example, defines "large" as in "large databases". Equally it is not clear how certain, everyday, software transactions should be treated, e.g. software copies acquired using licensing arrangements. Is a license, a license-to-use a software copy, or is it a license-to-use a software "original"? With the first interpretation a separate product (a software copy exists) but with the second a device that allows access to the "original" exists, not a copy. The lack of an exhaustive definition extends beyond specific transactions such as this however, indeed it impacts on most software transactions. There are two main reasons for this: "ownership" and "nomenclature".

\section{Ownership}

The SNA stipulates that (most) expenditure on products expected to be used in production for more than one year is investment, where ownership (real or imputed) of the asset is transferred from the seller to the buyer. However, most purchases of software reproductions usually include a license that permits the purchaser (only) to use the software and so, arguably, "ownership" is never transferred, stating that ownership resides with the owner of the software "original". From a users' perspective, however, an asset has been acquired. Statistical offices in different countries overcome this dichotomy differently. For improved international comparability, however, a common interpretation is needed.

\section{Nomenclature: descriptions used for software}

The descriptions for different types of software and computer services play a big role in determining whether any expenditure on software is capitalised or not. The SNA does not describe what software is in a physical sense and, since the descriptions and interpretations used for software vary considerably across countries, this is particularly problematic. For example, some countries capitalise "consultancy services" but others do not. 
1.2.4 These two areas relate to the lack of a definitive conceptual framework for software in the SNA, and such a framework is proposed in Annex A. But other differences in estimation matter too:

\section{Constant prices}

In most countries directly observable price indices are rarely available. Instead, proxy price indices are used and these differ significantly across countries, (see Figure 4).

\section{The estimation process for own-account (in-house) produced software}

Own-account production is estimated in nearly all countries on the basis of the costs of some, or all, of the inputs used in the production process: e.g. remuneration of staff involved in production. However the methods and assumptions used across countries vary significantly (see paragraph 1.3.5).

\section{The approach used for measurement - supply or demand}

Countries estimate investment in software using either a "supply" approach or a "demand" approach. The demand approach is the traditional route for investment - namely, that estimates are provided via businesses in investment surveys. However, the experience in most countries is that these surveys significantly underestimate investment, mainly, but not exclusively, because businesses do not capitalise own-account production. As such, many countries have resorted to using supply-based methods. These generally assume that investment levels can be determined by examining the total supply of software (broken down into sufficient product detail) entering an economy. So, for example, within the generic product description computer services, $100 \%$ of customised software services and $0 \%$ of hardware consultancy services might be capitalised. Partly because of the differences described under "nomenclature" above, these ratios differ across countries and contribute to the differences presented in Figure 2.

\section{The OECD questionnaire ${ }^{7}$}

1.3.1 To establish the scale of cross-country differences in these areas, a questionnaire was developed by the OECD and circulated in November 2001 to Task Force members. ${ }^{8}$ Four specific sections were covered: concepts, data, trade, and deflators. The results in each area are summarily discussed below.

\subsection{Concepts}

1.4.1 The questionnaire contained two tables that tried to capture the scale of differences in concepts. Table 1 below focused on the issue of "nomenclature", providing a list of commonly used software descriptions, inviting countries to state whether these software products were viewed as having asset characteristics: "Y or N"denotes the treatment/interpretation used by each participating country.

7. OECD Task Force on Software questionnaire. A synthesis paper summarising the returns from Task Force members is available on the Electronic Discussion Group set up by the OECD Task Force, as are all papers produced by the Task Force, access to this database can be made available by contacting "STDcontact@ oecd.org".

8. Task Force member countries: Australia, Austria, Canada, Denmark, Finland, France, Germany, Israel, Japan, the Netherlands, New Zealand, Norway, the United Kingdom, the United States, and Eurostat. 
1.4.2 It shows that unanimity exists in only two areas: (1) hardware consultancy and (2) software training. In fact for some countries the allocation of expenditure to investment may depend on other factors too, meaning that for some countries a ' $\mathrm{Y}$ ' and an ' $\mathrm{N}$ ' are recorded in the table below for some computer services products.

1.4.3 Table 2, below, set out to establish how certain transactions were recorded. Unanimity exists in four areas but, as will be demonstrated in section 4, this does not always mean that the treatment in practice is necessarily best in an accounting sense.

1.4.4 Together the two tables illustrate the degree of divergence in the treatment of expenditure on computer services products across NSOs and that this occurs for two reasons. The first reflecting the different interpretations given to the descriptions of computer services products, and the second reflecting differences in the conceptual framework. 


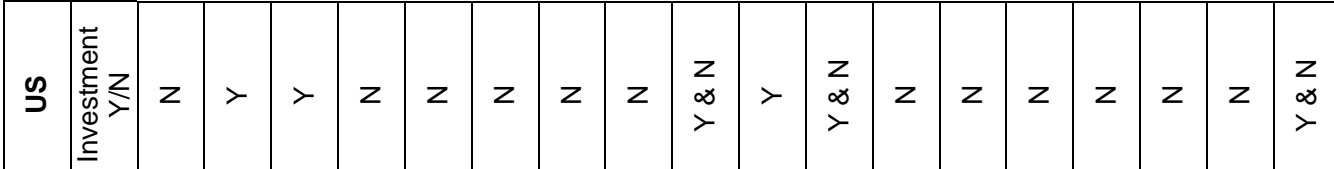

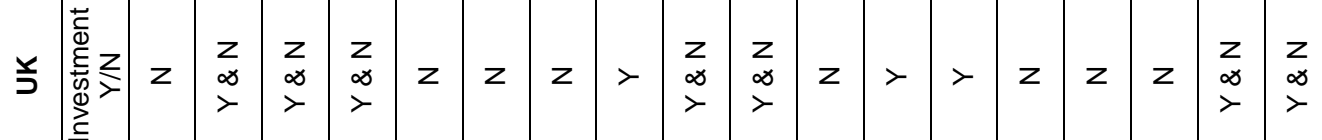

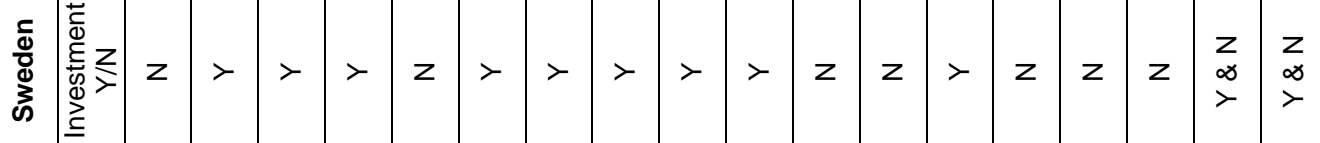

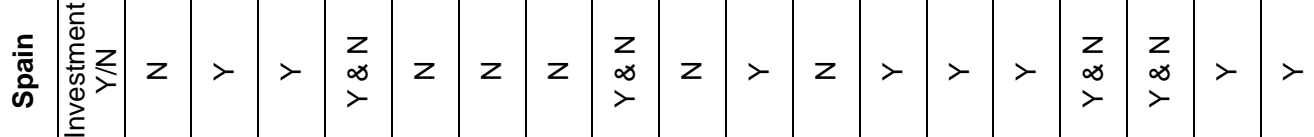

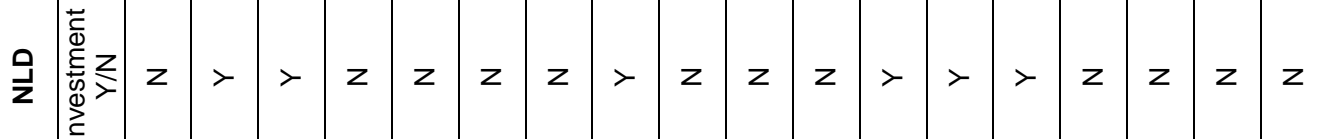

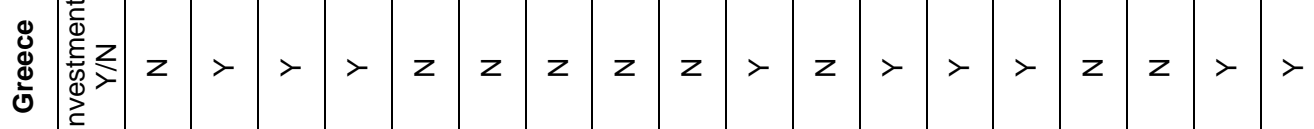

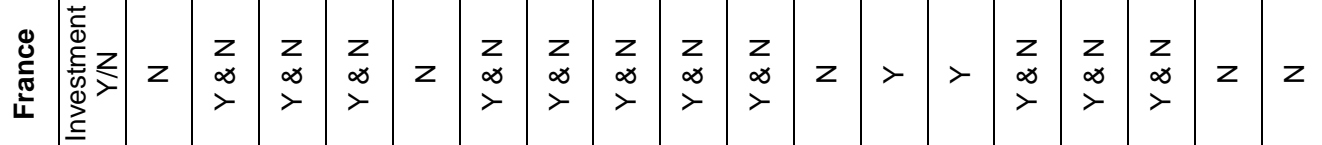

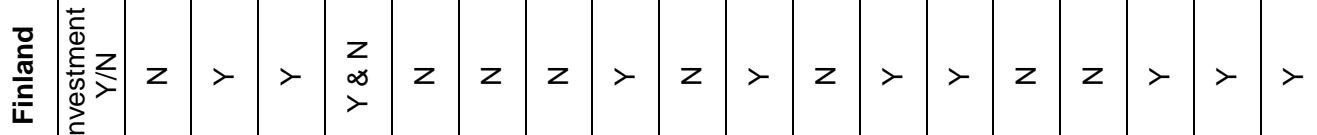

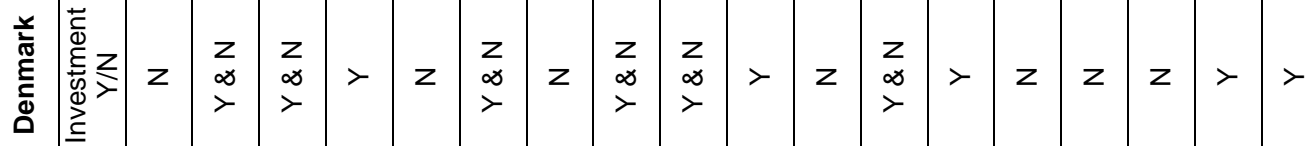

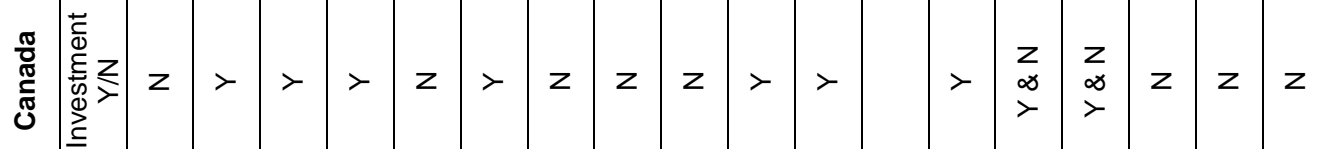

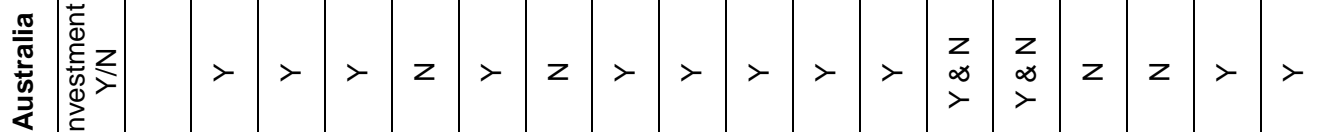

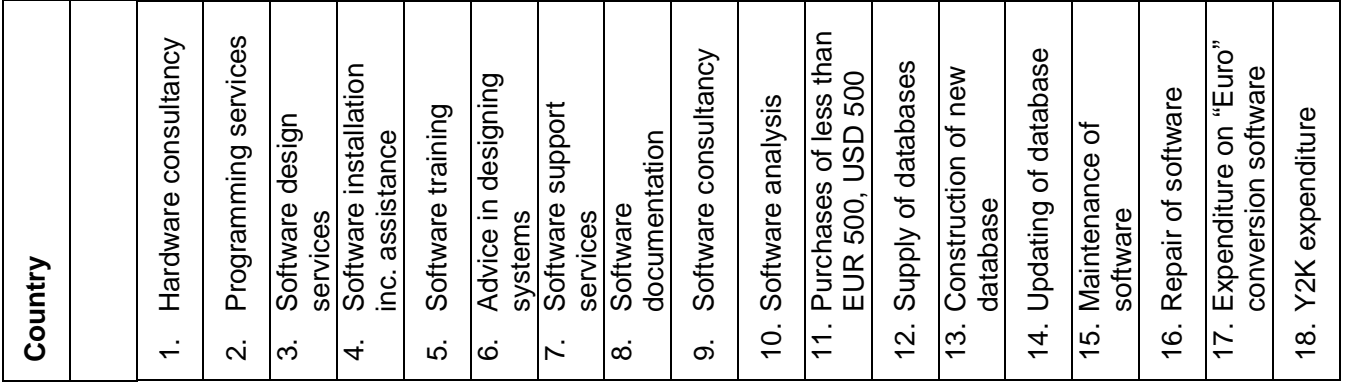




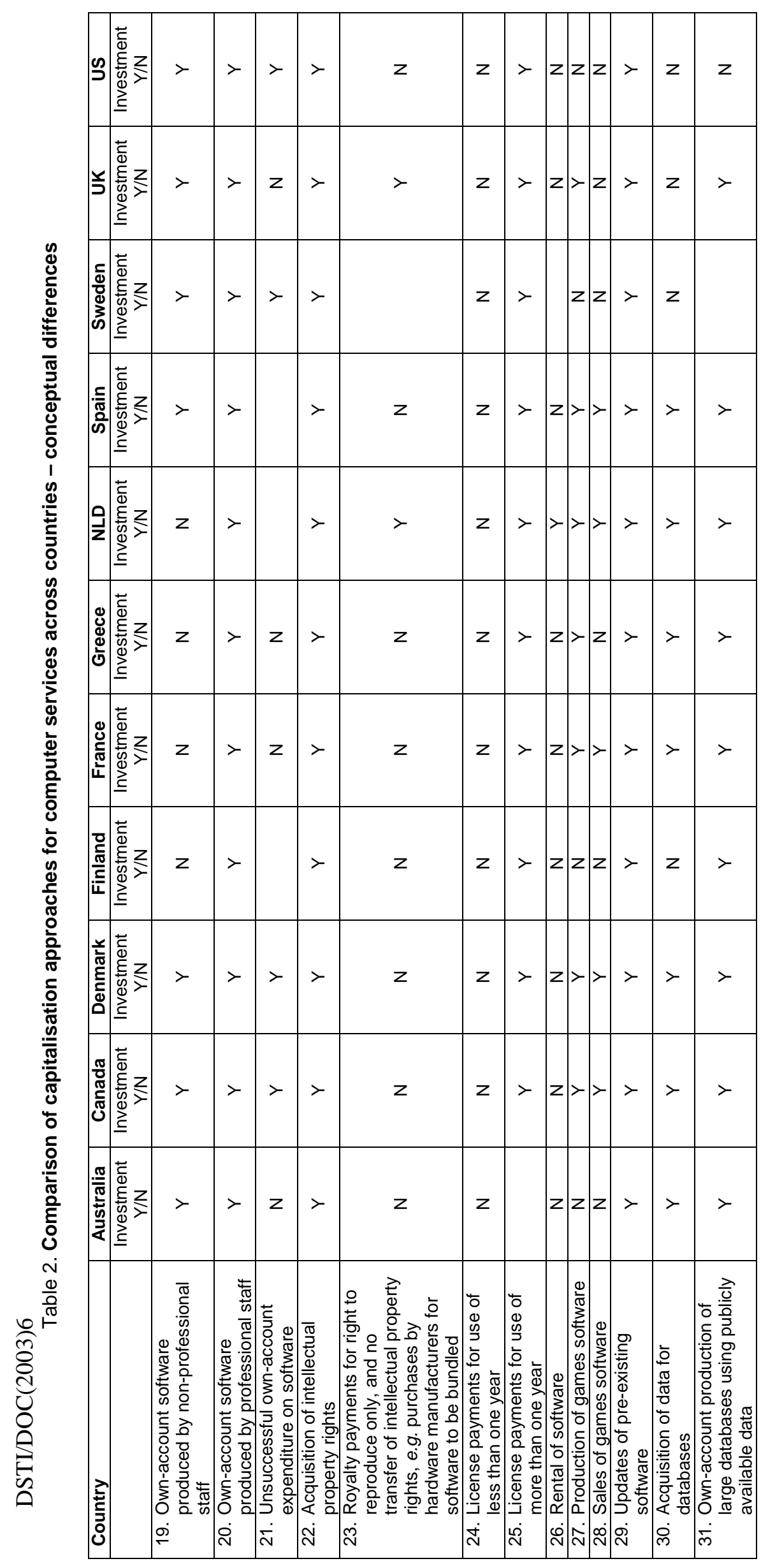




\subsection{Data}

1.5.1 Two specific sections were covered under the heading "data". The first set out to establish how many countries used a supply, as opposed to demand, approach, and, if possible, the difference in the size of estimates between the approaches, as well as the detail behind the supply approach. The second section focused mainly on the estimation methods for own-account production.

\section{Supply versus demand}

1.5.2 The returns to the questionnaire confirmed that only one Task Force country uses a demandbased method as routine. Other countries have experimented in the past with demand approaches using standard investment surveys but these attempts have generally been dropped in favour of supply approaches, since the demand methods were viewed as unreliable; producing estimates that were thought to be implausibly low.

1.5.3 In fact only four countries were able to provide demand-based estimates at all - Australia, Canada, France and the United States - giving, in itself, some indication on the dearth of demand information available. For Australia, supply estimates were seven times as high as the demand-based estimates, for Canada they were four times as high and for France (despite excluding a large proportion of software supply from their calculations) supply was about one-third higher. For the United States, the returned questionnaire referred to the US annual capital expenditure survey on businesses for 1998 which recorded an amount of USD 11.8 billion as "capitalised software purchased separately". This compares to the USD 123 billion estimate made by BEA using the supply approach.

1.5.4 However even within countries that use supply methods, differences in concepts and "other" differences impair comparability. The "other" differences mainly relate to the adjustments needed to avoid double counting when using the supply method, for example, specific adjustments are needed for the following transactions (see Annex A, paragraph A.3.2.1):

- Sales of software destined for resale.

- Sales of software based on subcontracts.

- Sales of software to software manufacturers.

- Sales of software to computer hardware and other machinery and equipment manufacturers.

Not all countries apply these adjustments, and even amongst those that do, estimation differences persist.

\section{Own-account software production}

1.5.5 Every country measured own-account software using an input method (except Japan, which was not able to provide estimates). In principle, this is supposed to include all production costs, intermediate or primary income (such as wages and salaries). However, not all countries do. All include wages and salaries as being the key determinant but many exclude intermediate costs.

1.5.6 But even the estimation process for wages and salaries differs. For example, the definition of an individual engaged in own-account production differs across countries (some definitions account for a wider pool of workers), as does the adjustment made to correct for the amount of time these individuals spend on other production activities, not own-account production, see Table 3 below. 
Table 3. Share of time spent on own-account software production

\begin{tabular}{lc}
\hline Country & Adjustment \\
\hline Australia & None \\
Canada & $50 \%$ \\
Denmark & None \\
Finland & None \\
France & $50 \%$ \\
Netherlands & None \\
Sweden & None \\
USA & $50 \%$ \\
\hline
\end{tabular}

\subsection{International trade}

1.6.1 In practice there are significant problems with the recording of imports of software, whether payments are for customised software, royalty payments for the rights to reproduce a software "original" (for example Microsoft Ireland paying Microsoft US for the rights to reproduce Windows 2000) or any other form of software. This mainly reflects the fact that "computer software" is not well identified in current international trade codes or balance of payments (BOP) items.

1.6.2 Indeed, although a number of items in the goods and services classification are relevant to computer software, it appears that significant and (usually) unidentifiable amounts are purchased described only as royalty payments.

1.6.3 The BoP system contains two codes where computer software services are likely to be recorded: 263 Computer Services and 266 Royalties and License Fees, which contains all royalties and license fees, not just those for software.

1.6.4 For a supply-based method it is important to separately identify software royalties, since these may include payments for imported software that should, arguably, be recorded as investment. For example, companies may purchase software copies from abroad by purchasing licenses that allow them to use software delivered electronically and, under most conditions (see Annex A, A.2.5), the view of the Task Force is that these payments should be recorded as investment and, arguably, as trade in goods. ${ }^{9}$ Although an implicit conclusion that can be drawn from the Software Task Force is that the distinction between goods and services, particularly in this context, is unhelpful. On the other hand, payments may be

9. See "International Merchandise Trade Statistics - Concepts and Definitions" 27, Goods used as carriers of information and software (HS heading 85.24). This category includes, for example, (a) packaged sets containing diskettes or CD-ROMs with stored computer software and/or data developed for general or commercial use (not to order), with or without a users' manual, and $(b)$ audio and videotapes recorded for general or commercial purposes (see paragraph 123 below for recommendation on valuation). However, (i) diskettes or CD-ROMs with stored computer software and/or data, developed to order, (ii) audio and videotapes containing original recordings, and (iii) customised blueprints, etc., are to be excluded from international merchandise trade statistics (see paragraph. 48 below).

123. There are international transactions which present special difficulties or questions regarding valuation of the goods involved. Some of the difficulties are due to the complexity of the transaction or the peculiarity of the goods. (...) The valuation of all goods should be made in accordance with the WTO Agreement on Valuation and the recommendations contained in the present publication (see paragraphs. 116 and 121 above). In addition, it is recommended that: ..... (b) Goods used as carriers of information and software, such as packaged sets containing diskettes or CD-ROMs with stored computer software and/or data developed for general or commercial use (not to order), be valued at the their full transaction value (not at the value of the empty diskettes or CD-ROMs, paper or other materials...). 
for the right to reproduce software, and in these cases, the Task Force took the view that these payments should be recorded as intermediate consumption of software, (see Annex A, A.2.3).

1.6.5 Table 4 below shows data on software goods, computer services and software royalties for a number of OECD countries. Columns 2 to 4 show the values used in BoP statistics and column 6 shows estimates of imported and exported software used in national accounts supply-use tables. Some countries, for example Greece, have consistent estimates suggesting that supply-based methods would not be affected by any misclassification of software. However others, e.g. Japan and the United Kingdom, do not.

1.6.6 That said differences between supply-use tables and BoP figures do not necessarily imply problems for supply methods per se. Canada, for example, records just over USD 1 million as imported software (CanSIC 5751 software products development) in its supply-use estimates but at least USD 1.5 billion in its BoP statistics. However it capitalises significant amounts of imported "royalties" separately within its supply-use framework even though they are not explicitly recorded as computer software imports in supply-use tables.

Table 4. Trade in software: good, services and royalties - (USD millions)

\begin{tabular}{|c|c|c|c|c|c|c|c|}
\hline \multicolumn{2}{|l|}{ Software product } & \multirow[t]{2}{*}{$\begin{array}{l}\text { Software } \\
\text { goods }\end{array}$} & \multirow[t]{2}{*}{$\begin{array}{l}\text { Computer } \\
\text { services }\end{array}$} & \multirow[t]{2}{*}{$\begin{array}{l}\text { Software } \\
\text { royalties }\end{array}$} & \multirow[t]{2}{*}{$\begin{array}{c}\text { Total } \\
\text { software }\end{array}$} & \multirow[t]{2}{*}{$\begin{array}{l}\text { Royalties } \\
\% \text { of total }\end{array}$} & \multirow[t]{2}{*}{ Supply-use } \\
\hline Country & Trade & & & & & & \\
\hline Australia & Import & 518 & 250 & 218 & 986 & 0.22 & 786 \\
\hline $1998-99$ & Export & 68 & 421 & 185 & 674 & 0.27 & 495 \\
\hline Canada & Import & 888 & 212 & 462 & 1562 & 0.19 & 1 \\
\hline 1998 & Export & 47 & 493 & 884 & 1423 & 0.62 & 1135 \\
\hline Denmark & Import & 131 & 74 & 289 & 493 & 0.59 & 419 \\
\hline 1997 & Export & 78 & 63 & 33 & 174 & 0.19 & 110 \\
\hline Czech Republic & Import & 107 & 129 & .. & 236 & .. & 195 \\
\hline 1999 & Export & 20 & 65 & .. & 85 & .. & 104 \\
\hline Finland & Import & 109 & 337 & $\begin{array}{l}. . \\
. .\end{array}$ & 446 & ... & .. \\
\hline 2000 & Export & 54 & 231 & ... & 285 & ... & $\begin{array}{l}. . \\
. .\end{array}$ \\
\hline France & Import & 842 & 627 & $\begin{array}{l}. . \\
. .\end{array}$ & 1469 & ... & $147 \ddot{3}$ \\
\hline 1998 & Export & 287 & 768 & $\begin{array}{l}. . \\
. .\end{array}$ & 1055 & $\begin{array}{l}. . \\
. .\end{array}$ & 1057 \\
\hline Greece & Import & 157 & 209 & $21 \ddot{8}$ & 584 & 0.37 & 584 \\
\hline 1998 & Export & 64 & 173 & 15 & 252 & 0.06 & 252 \\
\hline Italy & Import & 598 & 782 & .. & 1380 & .. & 1360 \\
\hline 1998 & Export & 35 & 286 & .. & 321 & .. & 300 \\
\hline Japan ${ }^{\star *}$ & Import & 591 & 3069 & .. & 3660 & .. & 614 \\
\hline 2000 & Export & 249 & 1569 & ... & 1818 & .. & 248 \\
\hline Netherlands ${ }^{* *}$ & Import & 519 & 366 & ... & 885 & ... & 1363 \\
\hline 1998 & Export & 798 & 442 & .. & 1240 & .. & 1421 \\
\hline Spain & Import & 264 & 494 & .. & 758 & .. & 1639 \\
\hline 1996 & Export & 52 & 187 & ... & 240 & .. & 1309 \\
\hline Sweden & Import & 161 & 544 & ... & 705 & .. & 1164 \\
\hline 1999 & Export & 91 & 681 & .. & 771 & .. & 1171 \\
\hline United Kingdom & Import & 1596 & 1556 & .. & 3152 & .. & 2600 \\
\hline 1999 & Export & 964 & 4006 & .. & 4970 & & 4618 \\
\hline United States & Import & 100 & 200 & 100 & 400 & 0.25 & 400 \\
\hline 1992 & Export & 2000 & 1400 & 1100 & 4500 & 0.24 & $2000^{*}$ \\
\hline
\end{tabular}

* US commodity flow data exclude trade in services in 1992

** Computer services includes information services.

1.6.7 Column 5 shows that most countries are not able to separately identify software royalties from total royalties in their BoP statistics, and for those that do, the contribution varies significantly, from $19 \%$ in Canada to 59\% in Denmark (for imports). How important this is depends on how much expenditure is on licenses-to-use, as opposed to licenses-to-reproduce. If predominantly the latter, then there is less cause 
for concern (as far as investment levels estimated using a supply approach are concerned, see Annex A, A.2.3).

1.6.8 Clearly, for improved international comparability, software needs to be separately identifiable in international trade classification systems. Chapter 3 of the OECD Final Report on Software provides more detail and recommendations on the types of changes needed to achieve this.

\subsection{Deflators}

1.7.1 Measuring price changes in software is inevitably difficult, reflecting its intangible nature and its rapidly changing characteristics, but it is doubly complicated by the fact that own-account software production has no observable market price. Figure 4 below compares price indices (fixed to $1995=100$ ) across countries. The differences are significant. For example, the index for Australia fell about $30 \%$ by 2000 but rose by about the same amount for Sweden. This largely reflects the dearth of price index information available in this area, and the alternative proxy deflators used, for example: general inflation price indices; office machinery price indices; the US pre-recorded software price index; and input methods (see Table 5).

Figure 4. Investment in software, price indices in recent years, $1995=100$

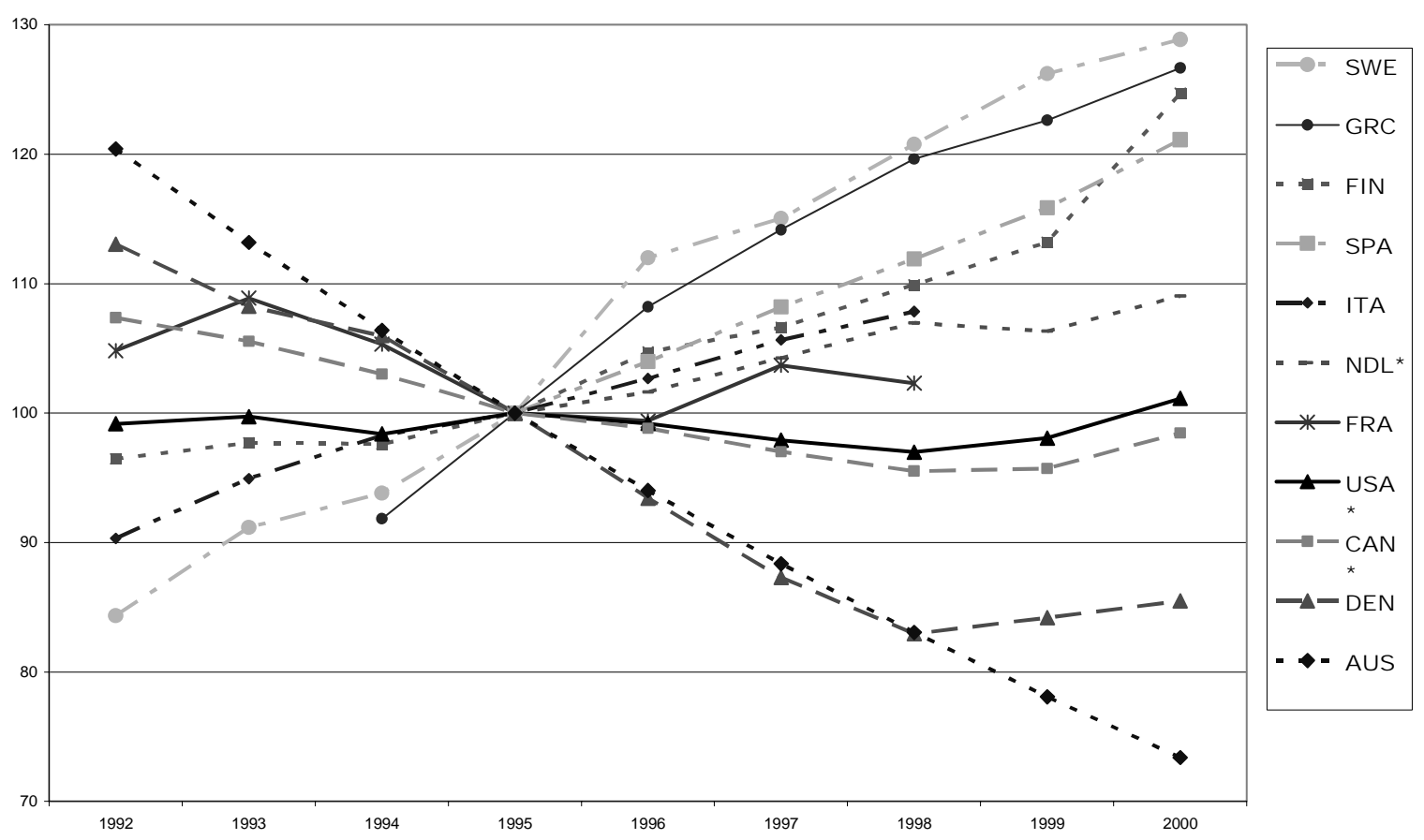

Source: OECD questionnaire on software.

1.7.2 Of the three software types described earlier, actual price indices are generally only available for pre-packaged software, and even here only in the United States (so far). The US experience is a good example of the difficulties involved in collecting and producing quality price indices for software: 
weighted hedonic and "matched pair" models ${ }^{10}$ were used for 1985-93 data, and matched models with a (3.3\%) bias adjustment thereafter (based on the observed difference between hedonic and matched pair indices in the years both were available, which differed significantly).

1.7.3 For the period 1985-93, the hedonic index was not applied alone because of concern that it would overstate price falls. When the characteristics of high-priced packages with limited sales were incorporated with lower priced packages with much greater sales, values derived from the high-priced packages had too high a weight. On the other hand, because the "matched pairs" price index is based only on overlapping products in two periods (ignoring new products and so not sufficiently representing actual products sold), price movements tend to be underestimated, hence the "averaging" of the two methods.

1.7.4 Price indices for customised software and own-account software are generally not available in any country; instead, countries largely use average earnings indices (sometimes weighted with prepackaged indices) as proxies. Eurostat draft regulations recommend that a "model" or "representative" pricing approach be used, recognising that capturing quality changes will still be a problem. But it is likely to be some time before countries are able to develop and implement price indices based on this approach. In the meantime therefore, at least, second-best methods are encouraged, for example:

- The use of average earnings indices in the computer software sector for customised and own-account software for own-use.

- The US index for prepackaged software adjusted for exchange rates, for software reproductions and "originals".

1.7.5 Encouraging the use of second-best methods in the short to medium term may seem unsatisfactory, and to some extent it is, but when set against the deflators currently in use across countries, even second best solutions represent a significant improvement, (see Table 5 below).

10. Matched pair models measure the relative price change by selecting products whose qualities and characteristics are constant over two periods of time. However, where these qualities/characteristics change rapidly, this may not be possible. Hedonic price indices attempt to overcome this by employing regressions between any product and its qualities/characteristics such that relative price changes with constant quality can be measured. However, hedonic price indices are extremely data-intensive and the regressions require regular re-evaluation. 
DSTI/DOC(2003)6

Table 5. Comparison of deflators used for software

\begin{tabular}{|c|c|c|c|c|}
\hline \multicolumn{2}{|l|}{ Country } & Own-account & Customised & Pre-packaged \\
\hline \multicolumn{2}{|l|}{ Australia } & \multicolumn{3}{|c|}{ Prices are assumed to fall by $6 \%$ a year. } \\
\hline \multicolumn{2}{|l|}{ Canada } & $\begin{array}{l}\text { Weighted average }(2: 1) \text { of } \\
\text { programmer labour costs } \\
\text { and non-labour inputs to } \\
\text { the computer services } \\
\text { industry. }\end{array}$ & $\begin{array}{l}\text { Weighted average of } \\
\text { own-account and } \\
\text { pre-packaged }(1: 3) \text {. }\end{array}$ & $\begin{array}{l}\text { Average of US index for } \\
\text { pre-packaged adjusted for } \\
\text { exchange rates. A new } \\
\text { index is due for release } \\
\text { next year. }\end{array}$ \\
\hline \multicolumn{2}{|c|}{ Czech Republic } & \multicolumn{3}{|c|}{ Price indices for the output of the computer services industry. } \\
\hline \multirow[t]{3}{*}{ Denmark } & \multirow{2}{*}{$\begin{array}{l}1993-95 \\
1996-97\end{array}$} & \multicolumn{3}{|c|}{ Weighted average of labour costs and PC hardware (1:1). } \\
\hline & & \multicolumn{2}{|c|}{ Weighted average labour and PC hardware (3:1). } & $\begin{array}{l}\text { Weighted labour and PC } \\
\text { hardware (1:1). }\end{array}$ \\
\hline & \multirow{2}{*}{$1998+$} & \multicolumn{3}{|c|}{ Geometric average of labour and hardware $(3: 1)$} \\
\hline \multirow[t]{2}{*}{ Finland } & & \multicolumn{3}{|c|}{ Average earnings index for the computer services industry. } \\
\hline & $1998+$ & \multicolumn{3}{|c|}{$\begin{array}{l}\text { Weighted average of labour costs of the computer services industry and US } \\
\text { pre-packaged software index adjusted for exchange rates. }\end{array}$} \\
\hline \multirow[t]{2}{*}{ France } & $1995(-)$ & \multicolumn{3}{|c|}{ US price index adjusted for exchange rates. } \\
\hline & $1995+$ & \multicolumn{3}{|c|}{ Labour costs. } \\
\hline \multicolumn{2}{|l|}{ Greece } & \multicolumn{3}{|c|}{ General (whole inflation) price index. } \\
\hline \multicolumn{2}{|l|}{ Japan } & \multicolumn{3}{|c|}{$\begin{array}{l}\text { Corporate Service Price Index for "the development of computer software tailored for } \\
\text { corporations", based on the labour costs. }\end{array}$} \\
\hline \multicolumn{2}{|c|}{ Netherlands } & $\begin{array}{l}\text { Labour costs of ICT } \\
\text { personnel. }\end{array}$ & Producer price index. & Producer price index. \\
\hline \multicolumn{2}{|l|}{ Spain } & \multicolumn{3}{|c|}{$\begin{array}{l}\text { Based on producer price index for office machinery and the general consumer price } \\
\text { index (excluding renting). }\end{array}$} \\
\hline \multicolumn{2}{|l|}{ Sweden } & \multicolumn{3}{|c|}{ Average earnings index for the computer services industry. } \\
\hline \multicolumn{2}{|c|}{ United Kingdom } & \multicolumn{3}{|c|}{$\begin{array}{l}\text { Average earnings series adjusted for the computer services industry with } 3 \% \\
\text { productivity adjustment since } 1996 \text {. }\end{array}$} \\
\hline \multicolumn{2}{|c|}{ United States } & $\begin{array}{l}\text { Weighted average (roughly } \\
1: 1 \text { ) of programmer labour } \\
\text { costs and non-labour } \\
\text { inputs to the computer } \\
\text { services industry. }\end{array}$ & $\begin{array}{l}\text { Weighted average of } \\
\text { own-account and } \\
\text { pre-packaged }(1: 3) \text {. }\end{array}$ & $\begin{array}{l}\text { Directly collected price } \\
\text { index (see above). }\end{array}$ \\
\hline
\end{tabular}


DSTI/DOC(2003)6

\section{HARMONISED ESTIMATES OF SOFTWARE}

\section{$2.1 \quad$ Overview}

2.1.1 The range of differences in estimation methods across countries highlights the importance of establishing a clearer set of rules for software estimation. In the longer term it is hoped that this will allow countries to return to using demand-based methods to estimate software. However this will take some time, particularly for own-account software, where it is likely that businesses will continue to be prudent in capitalising software on the basis of what is permissible for tax purposes. Full implementation will require redesigning business surveys and subsequent integration of these results and concepts within the National Accounts framework. As such, in the short to medium term, at least, it is likely that "supply" based methods will continue to be used. Annex A sets out the procedure recommended by the OECD Task Force and that countries are encouraged to adopt when estimating software using a supply method.

2.1.2 This section attempts to apply this procedure in order to illustrate the possible changes in software investment figures and GDP for selected countries by calculating harmonised estimates of software investment, in the sense that they are more comparable in an international context. The estimates presented below cannot, however, be interpreted as direct replacements for national authorities' own estimates. A number of assumptions are necessarily used for each country and further scrutiny by each country's statistical office may reveal that these are not always appropriate. For example, it is assumed below that total imports, as shown in the supply-use tables, include all royalties paid for software. The present paper did not take into account the new United States benchmark estimate.

2.1.3 Furthermore, it is important to note that some countries have already begun to revise the estimates of capitalised software used in their national accounts (in particular in the United States), in line with the recommendations made by the OECD Task Force, and so the numbers illustrated below for some countries may already be outdated. In addition, in producing estimates of investment ratios below, no adjustments have been made to correct for cross-country differences in:

- The degree of consolidation within the software producing industry.

- The tendency to bundle software.

- Licenses-to-reproduce, which are often recorded as royalties and not computer services.

2.1.4 It is difficult to determine how important these caveats are without the necessary data, earlier work, ${ }^{11}$ using input-output and supply-use tables, suggested that they did not significantly distort the comparability of investment ratios, and the analysis that follows makes this assumption.

11. Nadim Ahmad, "Measurement of Corporate and Government Expenditure on Gross Fixed Capital Formation and Intermediate Consumption: Software and Office Machinery", Room Document, OECD National Accounts Experts meeting, October 2001. 


\section{DSTI/DOC(2003)6}

2.1.5 That said, users of statistics interested in cross-country comparisons, particularly in investment, productivity, capital services and "new economy" issues should find the estimates provided below helpful since they provide more internationally comparable estimates.

2.1.6 Table 6 below revisits the current harmonisation problem by separately identifying purchased and own-account software. For European countries it also shows the investment ratio for CPA 72.2, the main product category in the European classification system which contains "capitalisable" software (see Annex B). In fact, excluding bundled and embedded software, this is almost exclusively where software capitalisation occurs, with some small insignificant exceptions.

Table 6. Software, purchased and own-account, percentage of GDP, investment ratios (official estimates)

\begin{tabular}{|c|c|c|c|c|c|c|c|}
\hline \multirow{3}{*}{ Country } & \multirow{3}{*}{ Year } & \multicolumn{4}{|c|}{ Purchased } & \multirow{3}{*}{$\begin{array}{l}\text { Own-account } \\
\% \text { of GDP }\end{array}$} & \multirow{3}{*}{$\begin{array}{c}\text { Total } \\
\% \text { of GDP }\end{array}$} \\
\hline & & \multicolumn{2}{|c|}{ CPA72.2 } & \multicolumn{2}{|c|}{ Total } & & \\
\hline & & $\begin{array}{l}\text { Investment } \\
\text { ratio }\end{array}$ & $\%$ of 72 & $\begin{array}{l}\text { Investment } \\
\text { ratio }\end{array}$ & $\%$ of GDP & & \\
\hline Czech Republic & 99 & 0.64 & 57 & 0.36 & 1.0 & & 1.0 \\
\hline Denmark & 97 & 0.58 & 61 & 0.36 & 0.8 & 0.7 & 1.5 \\
\hline Finland & 95 & & & & & 0.4 & 0.4 \\
\hline France & 98 & 0.51 & 34 & 0.17 & 0.4 & 0.3 & 0.7 \\
\hline Greece & 98 & & & 0.70 & 0.3 & & 0.3 \\
\hline Italy & 98 & 0.48 & 50 & 0.24 & 0.5 & 0.2 & 0.7 \\
\hline Netherlands & 98 & & & 0.39 & 0.9 & 0.4 & 1.3 \\
\hline Spain & 96 & & & 0.75 & 0.6 & 0.0 & 0.7 \\
\hline Sweden & 99 & 0.87 & 55 & 0.45 & 1.7 & 0.5 & 2.3 \\
\hline United Kingdom & 99 & 0.07 & 50 & 0.04 & 0.1 & 0.4 & 0.5 \\
\hline Australia & $98 / 99$ & & & & 1.1 & 0.5 & 1.5 \\
\hline Japan & 99 & & & & 1.3 & & 1.3 \\
\hline Canada & 98 & $0.95^{\star}$ & 46 & 0.41 & 0.8 & 0.4 & 1.2 \\
\hline United States & 97 & & & 0.37 & 1.2 & 0.6 & 1.8 \\
\hline
\end{tabular}

${ }^{*}$ Figures for Canada are based on the Canadian classification system, not the CPA, and are shown for illustration only.

2.1.7 Not all countries have been able to provide information that allows the calculation of the investment ratio for CPA72.2 but, in general, some tentative conclusions can be drawn from Table 6:

- The lower bound for the investment ratio for CPA72.2 is (about) 0.5, with the UK ratio an outlier.

- The percentage of supply of CPA 72.2 relative to total supply of computer services CPA72 is about $50-60 \%$, with France as an outlier.

- The investment ratio for total purchased computer services is about 0.4, with the United Kingdom, France, Greece and Spain as outliers.

- Own-account software estimates as a percentage of GDP differ significantly.

2.1.8 One way of examining the investment ratio for CPA72.2 is to consider the relationship between CPA72.2 and what can and cannot be capitalised. Annex A describes fully this relationship as agreed by the OECD Task Force. Six main categories exist for CPA72.2:

72.20.2 Programming services of packaged software products.

72.20.31 Systems and technical consulting services. 


\subsubsection{Custom software development services.}

72.20.33 Systems analysis and programming services.

72.20.34 Systems maintenance services.

72.20.35 Other professional computer-related services.

2.1.9 Broadly speaking, the Task Force recommended that most of CPA 72.20.2 (with the exception of payments for licenses-to-reproduce) should be recorded as investment. Indeed, it is possible that significant payments for licenses-to-reproduce are not recorded as CPA72.20.2 at all in the national accounts/business surveys of some countries but instead as unidentifiable royalties, reinforcing the position that most expenditure on this category will be, in practice, recorded as investment (if the recommendations of the Task Force are applied). The same is true for CPA 72.20 .32 and 72.20.33, with some exceptions fully described in Annex A. CPA 72.20.31, 34, and 35, on the other hand, are exclusively services that should be treated as intermediate consumption.

\subsection{Purchased software}

\section{France and CPA72.2}

2.2.1 The French ratio in column 2 of Table 6 is much lower than it is in other countries, where it is available. A priori one would expect this ratio to be broadly comparable across countries, irrespective of the variance in the tendency to capitalise, since it measures only the proportion of CPA72.2 supply relative to total CPA72 (computer services). Excluding France, the average for this ratio in other countries is 0.54.

2.2.2 This may indicate that France records a significant amount of expenditure, recorded as CPA72.2 in other countries, as "other expenditure", and not CPA72.2. This may explain France's low total investment ratio (0.17) for all computer services (column 3 ) but relatively average ratio (0.51) for CPA72.2 services. Indeed, the completed French questionnaire on software confirms that a significant amount of expenditure is recorded as expenditure on "software consultancy", not recorded as CPA72.2, and not considered within the French supply-based estimates as capitalisable expenditure.

2.2.3 Using the average for other countries, it is possible to broadly estimate how much of this expenditure on "software consultancy" would be recorded as CPA72.2 expenditure if the same interpretation of software consultancy were used for France as appears to be used in other countries. In 1998, total supply of CPA72 (excluding own-account production) was EUR 34.2 billion. In other countries at least half of this total is usually CPA72.2, so, by extension, we arrive at a figure of EUR 17.1 billion of CPA72.2 expenditure in France compared to the official figure of EUR 11.6 billion.

2.2.4 Assuming that the investment ratio for CPA72.2 of 51\% remains valid for this additional supply gives an extra EUR 2.8 billion of investment in France, or 0.2\% of GDP, in 1998.

2.2.5 This would raise France's overall investment ratio for purchased computer services to 0.25, compared to the current figure of 0.17 , still on the low side but closer to the central range of 0.4 in other countries, and significantly higher than the United Kingdom. In this context it is important not to overlook the fact that relatively small changes in the assumptions used for France would bring the overall investment ratio much closer to the central range. For example changing the ratios used from 0.51 and 0.5 to 0.6 , in both cases, would bring the overall investment ratio for purchased computer services for France up to 0.36 . 


\section{United Kingdom and CPA72}

2.2.6 The United Kingdom has by far the lowest investment ratio. The UK figures are based on survey data projected forward from 1991 using employment indicators. This process produced an estimate of GPB 3.127 billion in 1995. A later telephone survey was conducted and this revealed that companies had a 60:40 split between purchased software and own-account production. Further, it revealed that, even before the SNA93 change, companies had in fact been recording about $80 \%$ of software expenditure as investment in any case. The information in the 1991 survey was interpreted in a deliberately prudent manner but in the light of estimates produced by other countries it may have been too prudent. Indeed a number of UK national accounts users have commented on the relatively low UK software figures, in some cases producing alternative estimates ${ }^{12}$ which are in the same ball park as the estimates based on the OECD Task Force recommendations presented below.

2.2.7 In this regard, of particular interest is the ratio of "custom software", "semi-custom software" and "software products" (nomenclatures used in the 1991 survey) to total output (billings) of the computer services industry shown in the 1991 survey. This ratio, which is closely related to the investment ratio shown in (Table 6), column 3 above (if the Task Force recommendations are generally applied), is 0.36, roughly the same as the US ratio (which, for purchased software, uses methods broadly in line with the Task Force recommendations).

2.2.8 Indeed the SERVCOM inquiry results for the United Kingdom in 1999 reveal that of GBP 31.9 billion output by the computer services industry, GBP 2.9 billion was by industry 72002350 , "development of custom built application software products for customers", GBP 3.4 billion by 72002550 , "development of packaged application software products for customers i.e. programs developed and sold as a product (software licenses included)", GBP 1.1 billion by industry 72003550, "development of non-application software for customers (system software, tools, utilities) whether custom built or packaged (software licenses included)" and GBP 7.7 billion by industry 72004550, "IT consultancy services".

2.2.9 So, in total, over GBP 15 billion of output at basic prices was produced by industries that mainly produce software product CPA72.2. Assuming that most imported software in 1999 was CPA72.2 (as is generally the case), the total supply of CPA72.2 was $49.6 \%$ of total supply of computer services (by the computer services industry and imports) at basic prices. In purchaser's prices the total supply of computer services into the United Kingdom was GBP 36.2 billion, which, by extension, equates to GBP 18 billion of CPA72.2. Assuming that all other components of final demand (mainly exports) are also CPA72.2, and using the French investment ratio for CPA72.2 of 0.51 , total investment in purchased software would be estimated at GBP 7.75 billion, over six times the current published levels, giving an overall investment ratio of 0.23 ; roughly the same as France and Italy. And purchased software investment as a percentage of GDP would be $0.8 \%$, slightly lower than the United States but the same as Canada (which has a higher investment ratio).

2.2.10 Despite these changes, the (adjusted) UK ratio (0.23) would remain (but only marginally) the lowest of all the countries surveyed, and significantly below the ratios used in the United States and Canada. However, the ratio is acutely sensitive to the assumptions used in estimating the CPA72.2 investment ratio. For example, if we assumed that the CPA72.2 investment ratio in the United Kingdom was the same as in Denmark say, the overall investment ratio for purchased computer services, would be 0.29. Similarly, if the Swedish ratio was used, the overall investment ratio would rise to 0.43 , and total investment in purchased software would be equivalent to $1.7 \%$ of GDP.

12. For example, Nicholas Oulton, ICT and Capital Services in the UK, Bank of England, May 2001. 


\section{Greece and Spain - high investment ratios}

2.2.11 The very high ratios for Greece and Spain should be viewed in the context of the overall, and relatively small contribution of, purchased computer services in their economies. For example, Greece has the second highest investment ratio but the second lowest capitalisation of software as a percentage of GDP, possibly indicating that proportionally more non-CPA72.2 computer services are conducted in-house than they are in other countries. It is difficult to establish this proposition without detailed survey evidence but given the relatively small capitalisation levels, and the relatively low levels of own-account production, as a percentage of GDP, both Spain and Greece appear to be special cases as far as their investment ratios are concerned. For example, high investment ratios may be an indication of relatively low own-account production.

\subsection{Own-account software}

2.3.1 As demonstrated in section 2, the methods used for own-account software estimation are also very different, despite the fact that nearly all countries use largely the same estimation principle; that is, estimating the value on the basis of inputs used in own-account production. Table 7 below summarises the information used for own-account production estimates used in NSOs. It compares estimates of ownaccount software provided by Task Force members based on the Supply method (column 6) with official estimates (column 7) and estimates based on the Task Force recommendation (Column 12), (see Annex A, A.3.3).

2.3.2 At first sight, Table 7 points to significant changes to own-account software if the OECD Task Force recommendation is applied. However, the discussion that follows shows that significant caution is needed when applying the OECD recommendation since the data sources that underpin it (ISCO 213 employees and compensation of employees) appear to be interpreted differently across countries. 


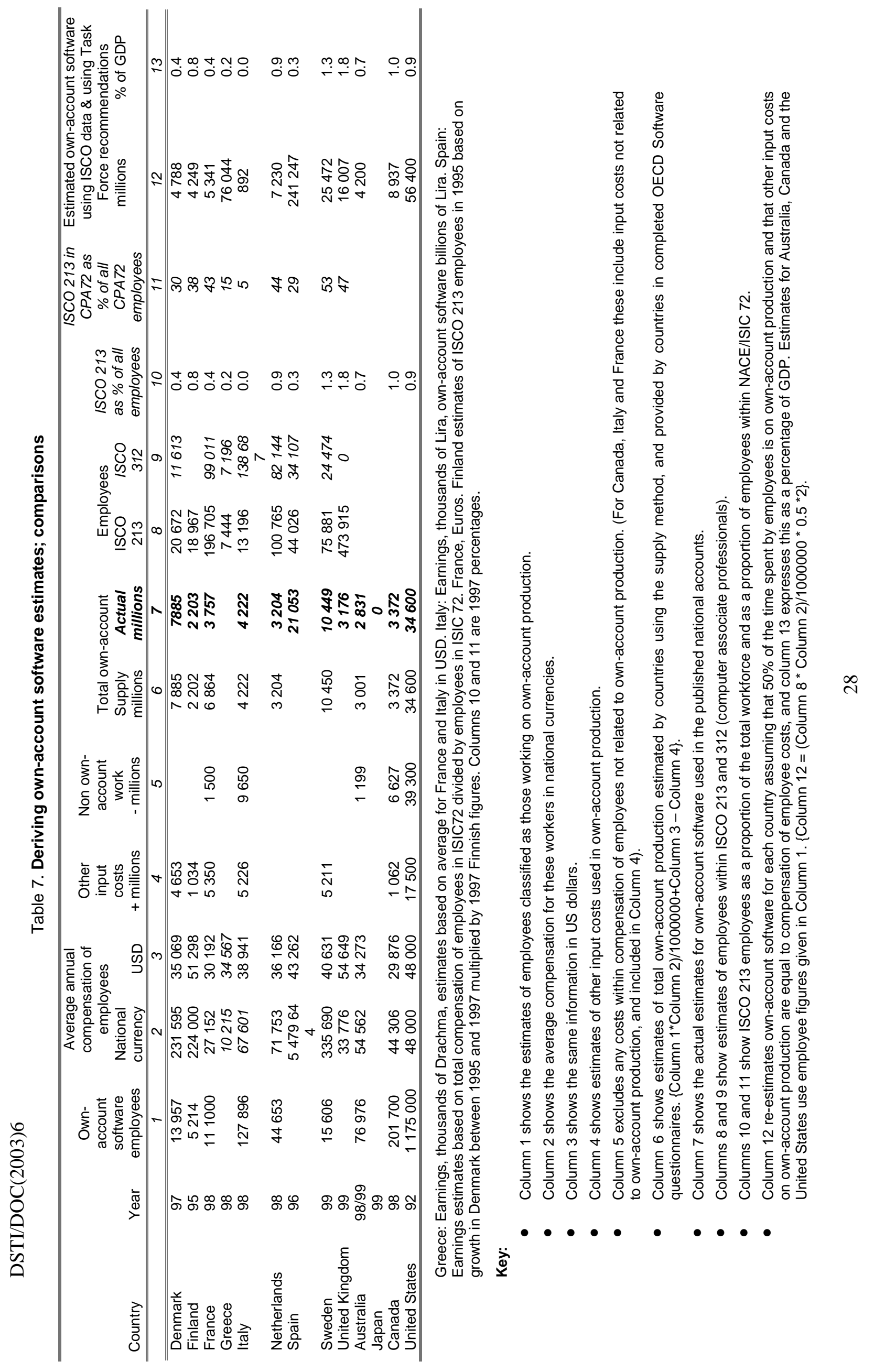


2.3.3 Table 8 compares estimates of own-account software, using the procedure described above (for column 13) with countries' official estimates. It shows that the "revised" harmonised estimates are significantly higher for most countries:

Table 8. Comparisons of own-account software estimates- percentage of GDP

\begin{tabular}{lcccc}
\hline Country & Year & $\begin{array}{c}\text { Original, (official), } \\
\text { data }\end{array}$ & $\begin{array}{c}\text { Estimates based } \\
\text { on Task Force } \\
\text { recommendations }\end{array}$ & Difference \\
\hline Denmark & 97 & 0.7 & 0.4 & -0.3 \\
Finland & 95 & 0.4 & 0.8 & 0.4 \\
France & 98 & 0.3 & 0.4 & 0.1 \\
Greece & 98 & 0.0 & 0.2 & 0.2 \\
Italy & 98 & 0.2 & 0.0 & -0.2 \\
Netherlands & 98 & 0.4 & 0.9 & 0.5 \\
Spain & 96 & 0.0 & 0.3 & 0.3 \\
Sweden & 99 & 0.5 & 1.3 & 0.7 \\
United Kingdom & 99 & 0.4 & 1.8 & 1.4 \\
Australia & $98 / 99$ & 0.5 & 0.7 & 0.2 \\
Canada & 98 & 0.4 & 1.0 & 0.6 \\
United States & 92 & 0.6 & 0.9 & 0.3 \\
\hline
\end{tabular}

- Denmark - The official figures for Denmark do not include an adjustment to correct for the time "own-account employees" spend on other activities. In effect, the Danes assume that $100 \%$ of time is spent on own-account activities. However, because only two-thirds of employees within ISCO 213 are used in the original Danish calculations, the impact of this assumption is to some extent mitigated. Further, the Danish method includes a mark-up factor of 2.47, compared to the mark-up factor of 2 used in "revised data" above.

- Finland, Netherlands, and Sweden - The official figures for these three countries are significantly lower than the alternative estimates presented in Table 8. This largely reflects the fact that the actual employee statistics used in the official figures are significantly lower than the corresponding ISCO 213 statistics (see below).

- United Kingdom/Italy - The official UK figures are not produced using a conventional "supply" approach as described above (see also paragraph 2.2.6), and the ISCO 213 figures shown above are almost certainly too high, particularly when one considers the zero entry for ISCO 312 . For Italy the position seems to be the opposite; hardly any employees are recorded as ISCO 213 but nearly all as 312 .

- Canada/United States - The national accounts estimates for Canada and the United States exclude own-account software "originals" for reproduction and other own-account software produced by software publishers. The view of the Software Task Force was that these assets, which amount to several billions of dollars, should in theory be capitalised. For example the returned Canadian questionnaire included an adjustment of CAD 4.3 billion to reflect the production of software linked to software sales. This adjustment includes own-account originals which should not be excluded, when applying the OECD recommendations. At the same time the Canadian figures include an adjustment of just over CAD 1 billion to reflect other production costs, such as intermediate consumption, etc. This compares with the value of total compensation of employees engaged in software production of CAD 9 billion. For most countries (and indeed in most industries/production processes) the ratio of other production costs to compensation of employees is much higher, and usually about 1:2 (the United States, for example, uses a mark-up factor of 2.02, equivalent to a ratio of 1:2). If we assume that the CAD 4.3 billion figure has also been estimated on this basis, a more realistic value for the value of software production linked to 
software sales would be about CAD 7.75 billion, a significant proportion of which, would be expected to be own-account originals.

\section{ISCO 213 as the basis for estimation}

2.3.4 Clearly the use of ISCO213 as the basis for estimating better harmonised estimates of ownaccount software is limited in practice.

2.3.5 The data for Italy (see Table 7) well illustrates the problem. According to the ISCO statistics for Italy only $0.1 \%$ of employees work as ISCO 213 (compared to about $1 \%$ for most other countries). On the other hand the position is reversed when looking at ISCO 312, where significant employees are recorded in Italy. It seems fair to assume, therefore, that large numbers of employees who would be classified as ISCO 213 in other countries are instead recorded as ISCO 312 in Italy. This conclusion is to some extent confirmed when looking at the Italian Statistical Office's own estimates of employees working on ownaccount software (Table 7, column 1), which are very close to the ISCO 312 estimates. Using the figures in column 1 for Italy, and applying the harmonised calculation used in column 12, gives a figure of ownaccount investment ten times as high as the estimated figure shown in Table 7 (column 12), and about twice as high as the supply figures derived by ISTAT in column 7 (ITL 8646 billion as opposed to ITL 4222 billion).

2.3.6 On the other hand, the ISCO 213 figures for the United Kingdom are at the other end of the spectrum, since no employees are recorded within 312 at all. Given the relatively high ratio of employees in 213, compared to the total workforce, it is likely that most, if not all, 312 employees are instead recorded as ISCO 213 in the United Kingdom, and so the estimates shown in column 12 of Table 7 are almost certainly too high. Estimates from the UK Labour Force Survey for 1999 show that in Autumn 1999, 121000 employees were recorded as software engineers and 102000 as computer analysts programmers, a total of 223000 , less than half the ISCO 213 figures shown in Table 7.

2.3.7 Using these figures as the basis for estimating UK own-account software would bring ownaccount software estimates down to GBP 7.5 billion or $0.8 \%$ of GDP, roughly twice as high as the estimates currently published in the UK national accounts. To some extent a similar case could be made for Sweden, which has particularly high levels of employees in ISCO 213 compared to ISCO 312. Excluding Italy, on average (by country), about $40 \%$ of all employees in ISCO 213 and 312 combined are classified as 312. So, assuming that only 60\% of all employees in ISCO 213 and 312 in Sweden are actually employed in ISCO 213, would bring own-account software down to 1\% of GDP down, compared to the $1.3 \%$ shown above. Applying the same procedure to Finland would bring the estimate of own-account software down to just under $0.5 \%$ of GDP.

\section{Differences in compensation of employees}

2.3.8 Harmonisation problems go further than this however. For example, compensation figures for France and Canada are significantly below levels in other countries, implying that the coverage of compensation of employees is not the same across countries. Indeed INSEE has recently reviewed the estimates for compensation of employees used above, which do not include social contributions, and provided new figures of EUR 55 000, increasing own-account production to $0.75 \%$ of GDP. The Canadian figures are also low but these may reflect in part the weakness of the Canadian dollar, which lost about one-quarter of its value relative to the US dollar between 1992 and 1998. 


\subsection{Total investment: harmonised using Task Force recommendations}

2.4.1 Table 9 below reproduces Table 6 with "harmonised" estimates for purchased software and own-account software, including adjustments described in paragraphs 2.3.4-8 above; with an estimate of $0.6 \%$ of GDP for own-account software production in Japan based on the average in other large countries, since Japan does not currently include estimates of own-account software within its GDP.

\section{Table 9. Estimates of investment in software as percentage of GDP (and investment ratios) using the Task Force recommendations}

\begin{tabular}{|c|c|c|c|c|c|c|c|c|}
\hline \multirow[b]{3}{*}{ Country } & \multirow[b]{3}{*}{ Year } & \multicolumn{4}{|c|}{ Purchased } & \multirow{3}{*}{$\begin{array}{l}\text { Own- } \\
\text { account } \\
\% \text { of } \\
\text { GDP }\end{array}$} & \multirow{3}{*}{$\begin{array}{l}\text { Total } \\
\% \text { of } \\
\text { GDP }\end{array}$} & \multirow{3}{*}{$\begin{array}{l}\text { Implied } \\
\text { increase } \\
\text { on official } \\
\text { estimates, } \\
\% \text { of GDP }\end{array}$} \\
\hline & & CPA7 & & To & & & & \\
\hline & & $\begin{array}{l}\text { Investment } \\
\text { ratio }\end{array}$ & $\%$ of 72 & $\begin{array}{l}\text { Investment } \\
\text { ratio }\end{array}$ & $\begin{array}{l}\% \text { of } \\
\text { GDP }\end{array}$ & & & \\
\hline Czech Republic & 99 & 0.64 & 57 & 0.36 & 1.0 & & & \\
\hline Denmark & 97 & 0.58 & 61 & 0.36 & 0.8 & 0.4 & 1.3 & -0.3 \\
\hline Finland & 95 & & & & & 0.4 & & 0.1 \\
\hline France & 98 & 0.51 & 50 & 0.25 & 0.6 & 0.8 & 1.5 & 0.8 \\
\hline Greece & 98 & & & 0.70 & 0.3 & 0.2 & 0.5 & 0.2 \\
\hline Italy & 98 & 0.48 & 50 & 0.24 & 0.5 & 0.4 & 0.9 & 0.2 \\
\hline Netherlands & 98 & & & 0.39 & 0.9 & 0.9 & 1.8 & 0.5 \\
\hline Spain & 96 & & & 0.75 & 0.6 & 0.3 & 0.9 & 0.3 \\
\hline Sweden & 99 & 0.87 & 55 & 0.45 & 1.7 & 1.0 & 2.7 & 0.5 \\
\hline United Kingdom & 99 & 0.51 & 50 & 0.23 & 0.8 & 0.8 & 1.7 & 1.2 \\
\hline Australia & $98 / 99$ & & & & 1.1 & 0.7 & 1.8 & 0.2 \\
\hline Japan & 99 & & & & 1.3 & 0.6 & 1.9 & 0.7 \\
\hline Canada & 98 & 0.95 & 46 & 0.41 & 0.8 & 1.0 & 1.8 & 0.6 \\
\hline United States & 97 & & & 0.37 & 1.2 & 0.9 & 2.1 & 0.3 \\
\hline
\end{tabular}

2.4.2 Figure 5 compares total figures for software investment as a percentage of GDP. It shows that applying the Task Force recommendations (with modifications for own-account software as described above to correct for data-quality) would lead to increases in estimates of software investment as a percentage of GDP by over $0.25 \%$ of GDP in nearly all countries, about $0.5 \%$ to $0.75 \%$ of GDP in France, Netherlands, Sweden, Japan and Canada, and over $1 \%$ in the United Kingdom. 
Figure 5. Comparison of estimates of investment in software, percentage of GDP (official estimates versus estimates based on Task Force recommendations)

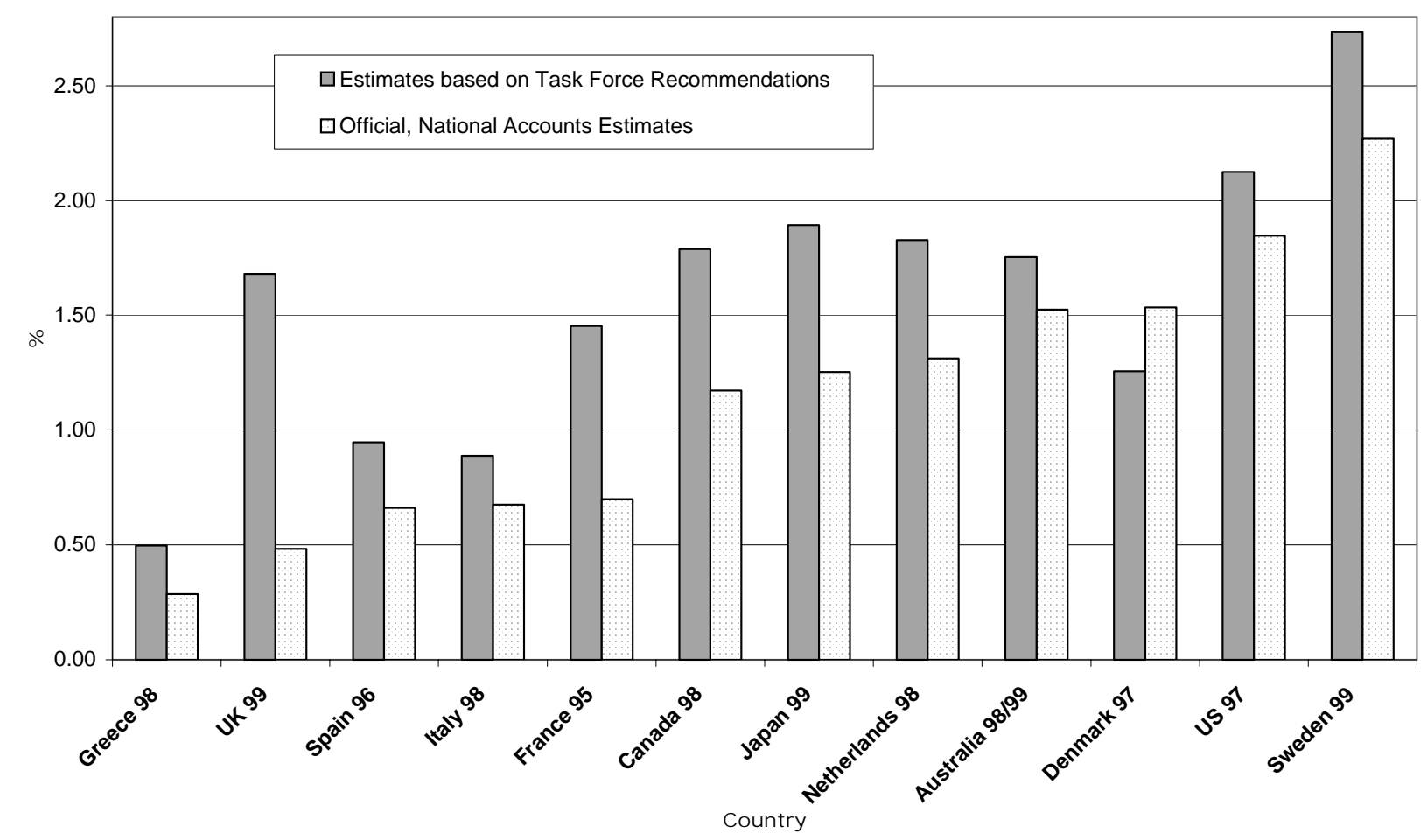

2.4.3 Although the implied changes are significant it should be remembered that the revised estimates, based on the Task Force recommendations, include estimates for purchased software derived using relatively prudent assumptions. For example, revised investment ratios for France and the United Kingdom remain well below those used in most other countries (about 10-15\% lower). Relatively small changes in the size of these assumptions can have significant impacts on software investment to GDP ratios.

2.4.4 This is illustrated in the following two graphs by using more transparent assumptions. The first uses an average investment ratio for purchased software (set equal to 0.4), and the second looks at the impact of using the UK ratio for purchased software (0.04). The significant changes in the resulting share of software investment in GDP provide evidence of the sensitivity of software investment as a percentage of GDP to the investment ratio.

2.4.5 Figure 6 below compares National Accounts estimates of software investment, as a percentage of GDP, with those based on the assumption that the software ratio in all countries is 0.4 (using harmonised estimates for own-account software). As expected, the implied change for the United Kingdom, Italy and France increases significantly. The United Kingdom moves from having the second lowest percentage to the second highest. 
Figure 6. Comparison of estimates of investment in software, percentage of GDP (official estimates versus estimates based on Task Force recommendations, with a harmonised investment ratio of 0.4 )

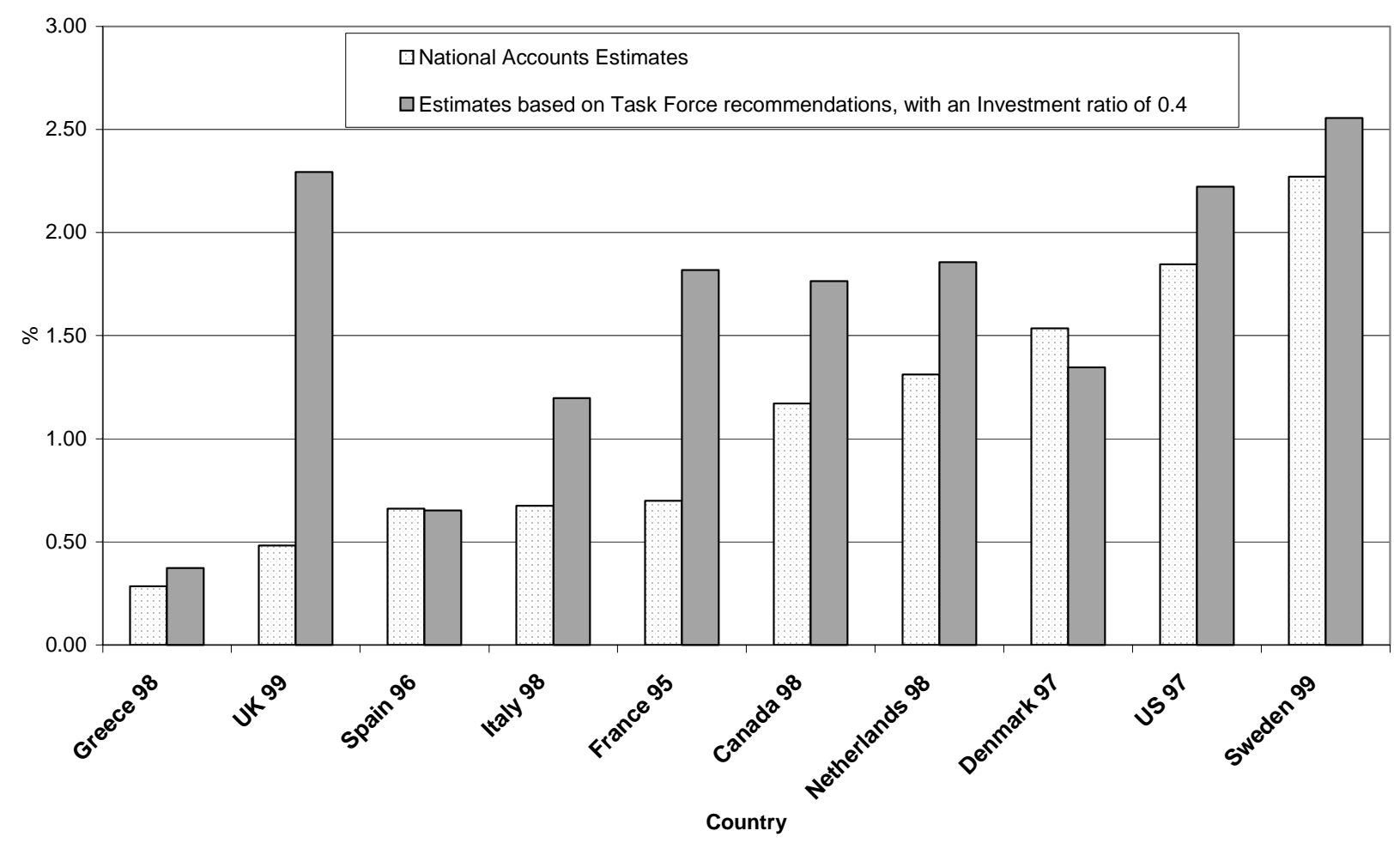

2.4.6 However, it is important to recall that not all of the recommendations of the software Task Force have been agreed. In particular the treatment of software reproductions remains open. In this context Figure 7 below illustrates the size of change that might occur to country estimates if software reproductions are not capitalised. The UK investment ratio is assumed to be representative of the investment ratio that might be expected in other countries if harmonisation was reached in this way, with "harmonised" estimates presented, including changes to harmonise own-account software production. Using the UK ratio would imply significant changes to the estimates currently used in most countries, even though for some countries the impact is dampened slightly by offsetting changes on own-account software. 
Figure 7. Comparison of estimates of investment in software, percentage of GDP (official estimates versus estimates based on the UK investment ratio for purchased software $(0.04)$ and the Task Force Recommendation for own-account software)

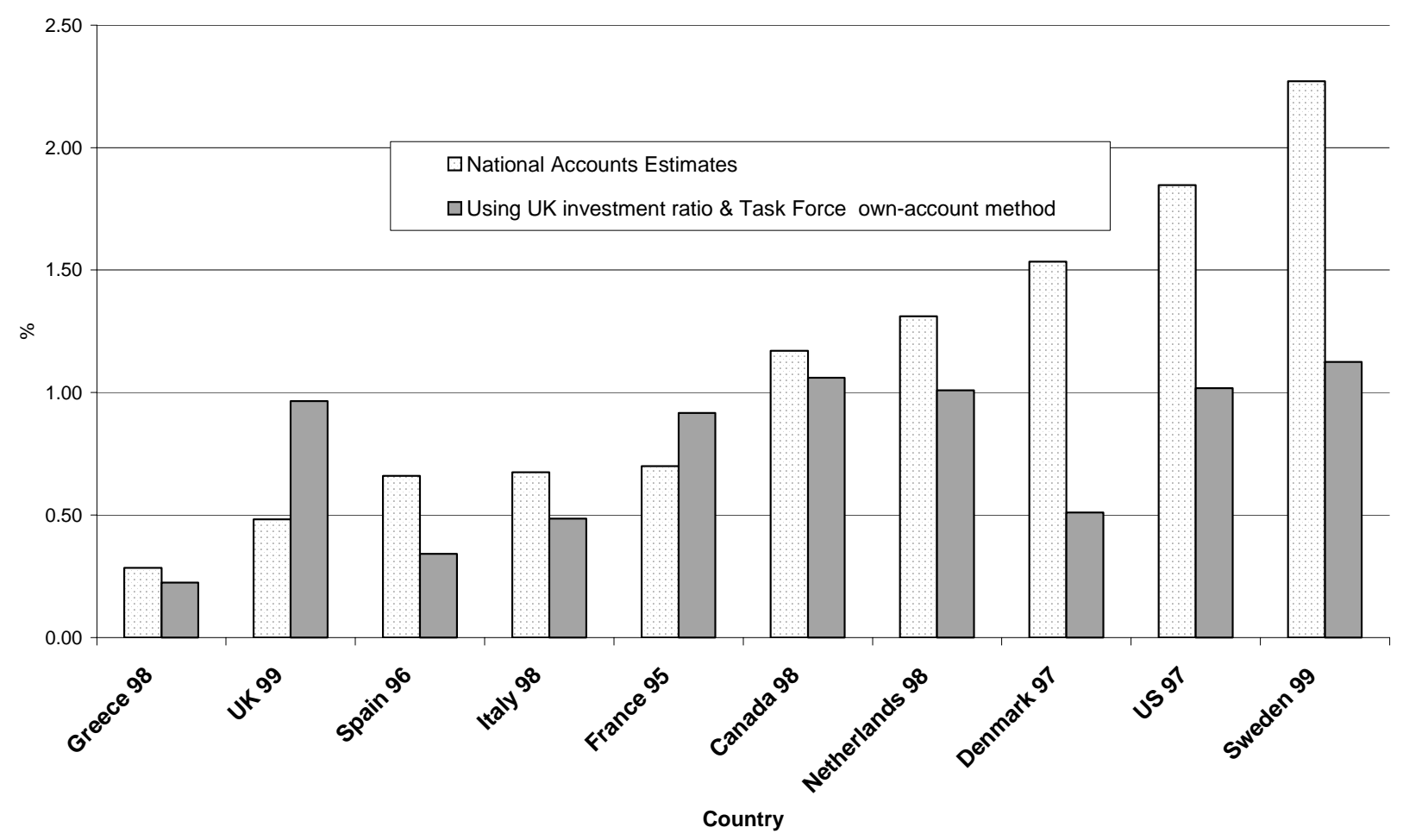

2.4.7 The impact on GDP levels of introducing harmonised software estimates is likely to be considerable for some countries. This is critically dependent on whether software reproductions are capitalised, and on the assumptions used to calculate own-account software. For example, using an investment ratio of 0.4 and the Task Force's recommended procedure for own-account software to calculate software investment in the United Kingdom, increases GDP by over $1 \%$ of current official estimates for the late 1990s. However, it is important to recognise that this assumes no other offsetting changes are found. In some countries, for example, the total levels of investment used in demand-based surveys (own-account production excepted) are considered to be fairly robust, but the allocation to specific asset types less so. In this regard an increase in purchased software investment may result in a decrease in investment in other asset categories, the overall effect being negligible (or no) change to total investment and GDP; changes to own-account production estimates will however usually result in an increase in GDP. For example, when the United Kingdom and Canada first included estimates of software investment, they discovered that some software had already been previously recorded by businesses as investment but allocated to different asset types in official statistics. Therefore the overall change to GDP in both countries was less than the level of software capitalisation. In this analysis, any changes to software investment are assumed to increase investment levels and GDP in their entirety.

\section{$2.5 \quad$ Growth}

2.5.1 Although the impact on levels are important so too is the impact on growth (in constant prices). Figure 8 below shows the estimated impact on growth in the United States, assuming an investment ratio of 0.04 (which is the one currently used in the United Kingdom), and for the United Kingdom, assuming investment ratios of 0.23 and 0.4 respectively. In both cases, the OECD Task Force procedure for own- 
account production is applied, and a number of assumptions ${ }^{13}$ are necessarily used. Table 10 shows the size of changes in each year.

Table 10. Estimated changes to GDP growth rates (constant prices), compared to official estimates, percentage of GDP

\begin{tabular}{lcccccccc}
\hline Year & 1993 & 1994 & 1995 & 1996 & 1997 & 1998 & 1999 & 2000 \\
\hline $\begin{array}{l}\text { Change in UK GDP growth rate assuming an } \\
\text { investment ratio of (0.23) }\end{array}$ & 0.0 & 0.1 & 0.1 & 0.1 & 0.3 & 0.1 & 0.3 & 0.0 \\
$\begin{array}{l}\text { Change in UK GDP growth rate, assuming an } \\
\text { investment ratio of (0.4) }\end{array}$ & 0.0 & 0.1 & 0.1 & 0.1 & 0.4 & 0.2 & 0.4 & 0.0 \\
$\begin{array}{l}\text { Change in US GDP growth rate, assuming an } \\
\text { investment ratio of (0.04) }\end{array}$ & 0.0 & -0.1 & -0.1 & -0.2 & -0.3 & -0.3 & & \\
\hline
\end{tabular}

2.5.2 Although in some years GDP growth rates would change by over +/-0.25\% of GDP, the trend of GDP growth rate remains, reassuringly, largely unaffected. That said, the change in growth due to the different assumptions used is unlikely to be as large for 2000 onwards, since expenditure on computer services since 1999 is likely to have stabilised (indeed for the UK estimates of GDP growth would be largely unaffected in 2000):

1. Because the rapid growth in computer services is unlikely to continue (at least at the same pace).

2. Much of the growth in 1999 was probably due to exceptional expenditure on Y2K.

2.5.3 Equally, some of the estimated change to GDP growth rates reflects software investment by government. Changes of software expenditure from intermediate consumption to investment in these circumstances would overstate the possible sizes of the change to growth rates shown above, because of the way in which government output in current prices is calculated in the national accounts. In these circumstances GDP would only increases/decreases by the imputed capital consumption of the reclassified investment.

13. UK information based on ONS supply-use tables 1992-2000. Revised own-account estimates are projected from 1999 using growth in ISCO 213 figures. Purchased software estimates are deflated using the US price index for purchased software adjusted for changes in the US/UK exchange rate. US figures have been calculated using BEA statistics on customised and purchased software to estimate total supply of computer services in non-inputoutput years, assuming that the investment ratio for purchased software in 1997 is stable throughout the period of time shown above. Own-account estimates deflated using an average of the US price index for purchased software and a price index that rises by $5 \%$ per annum (to approximate wages and salaries, without any productivity assumptions/adjustments). 
Figure 8. Sensitivity of GDP growth rates to different investment ratios for purchased software

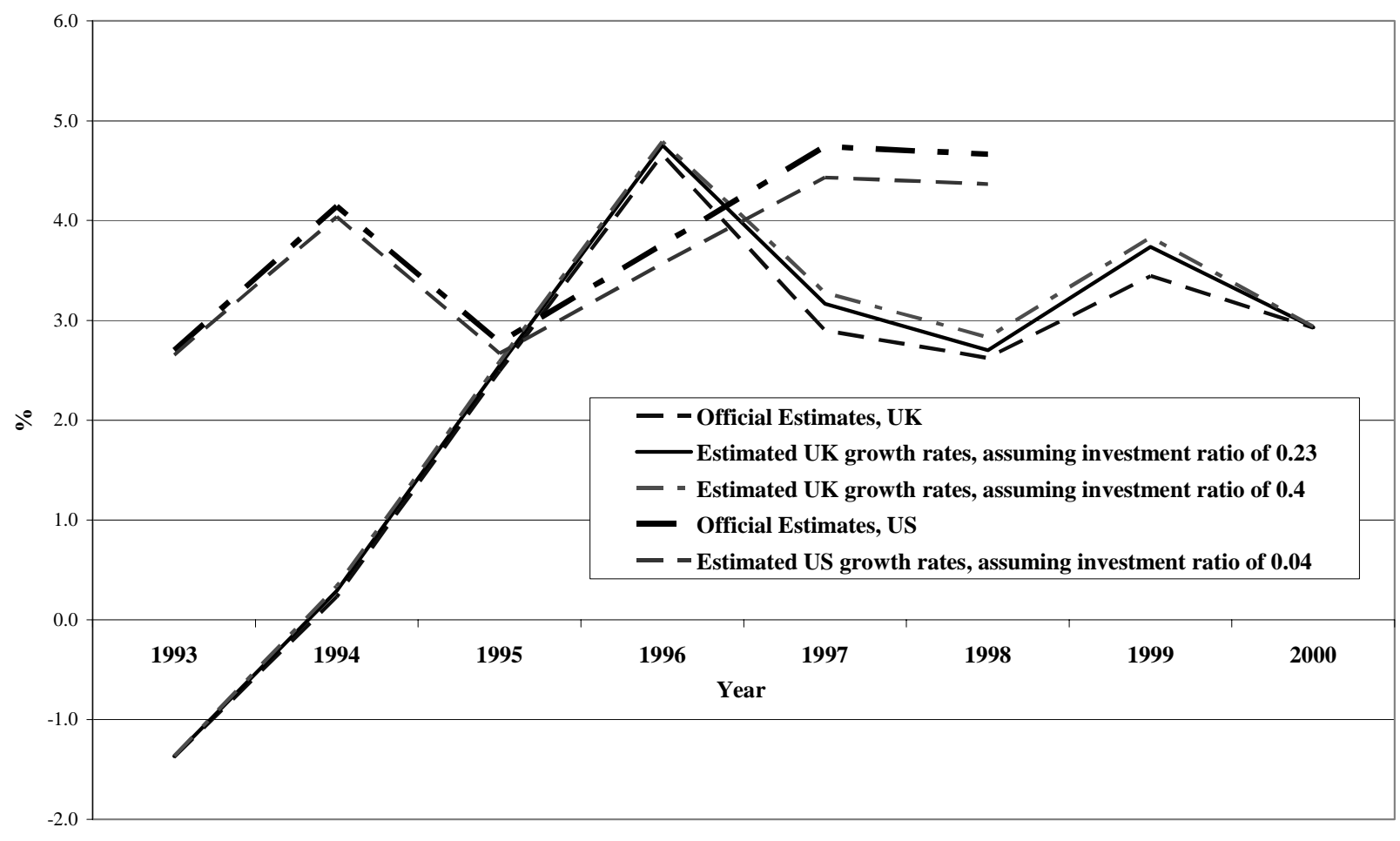

2.5.4 The impact on other countries is not assessed in this paper; however, similar results are likely to occur depending on the size of the investment ratio in each country and the harmonised approach used, so changes of between $+/-0.25 \%$ of GDP would be expected. For example, the Netherlands (with a similar investment ratio and (harmonised) own-account and purchased software (as a percentage of GDP) would be expected to have similar reductions in growth rates as those exhibited by the United States if the UK investment ratio is applied (assuming that growth in software demand is similar in both the US and the Netherlands). In the same way, for France, increases in GDP growth rates would be expected if an average investment ratio of 0.4 were applied. ${ }^{14}$ In all cases the impact on growth rates is likely to be smaller post 1999/2000, assuming that software expenditure has stabilised to grow at about the same rate as the economy generally. However, if the slowdown in computer expenditure since 1999 (Y2K expenditure) was precipitous, resulting in a negative contribution to overall GDP growth, the direction of change can be expected to reverse.

14. This is similar to the results shown in Lequiller 2001, "The New Economy and the Measurement of GDP Growth", Graph 8. Changes to French GDP growth rates are shown to increase from $0.1 \%$ in 1995 to $0.2 \%$ in 1998, by applying the US investment ratio to French software estimation. Equally US GDP growth rates are shown to fall by $0.05 \%$ and $0.2 \%$ respectively over the same period, using the French investment ratio. 
DSTI/DOC(2003)6

\section{CONCLUSION}

3.1 It is clear that at present estimates of software investment across countries are largely incomparable because of inconsistencies in the assumption used to estimate software. The recommendations made by the OECD Task Force should improve comparability of software estimates across countries but as demonstrated above this will not be easy. There are two strands to the harmonisation process. The first is largely complete, agreeing on the conceptual framework for recording software, which the Task Force Report provides. The second strand however, using the framework to estimate software, will take longer to achieve, since it is dependent on improving data quality in a number of areas.

3.2 The first is international trade. Section 1 illustrated that international trade classification systems do not explicitly identify trade in software. The size of this problem, for GDP and investment, is difficult to assess; if much of the trade is in licenses-to-reproduce then the impact is likely to be limited. It has not been possible to fully address this issue in the context of this paper, largely reflecting the size of measurement difficulties, but the importance of international trade in this context should not be underestimated.

3.3 The supply-based method for purchased software also require other significant data improvements and/or data assumptions. For example, supply data at a very disaggregated product level is needed, ideally sub-four-digit (see Annex A), with more detailed descriptions in some areas, for example differentiating between supply of licenses-to-use and licenses-to-reproduce, data on subcontracts and data on the supply of bundled software. The analysis in section 2 made no attempt to do this, instead it focused, largely, on the investment ratio for CPA72.2. Cross-country differences in the degree of subcontracting or bundling, for example, may explain why investment ratios have remained relatively different in the analysis above, even after adjustments have been made.

3.4 The OECD plans to circulate a questionnaire within the next two years to establish how far countries have moved in adopting the recommendations of the Task Force. The measure of this movement will be a comparison of investment ratios, where it is hoped there will be a convergence.

3.5 In practice, for own-account software considerable harmonisation problems remain, particularly regarding the lack of harmonisation in ISCO 213 estimates across countries. In this context, countries are encouraged to compare their own national ISCO 213 (and 312) estimates with other countries and with estimates of employees working on own-account software based on other survey information, to ensure that the quality of their own-account estimators compares favourably with other countries. 
DSTI/DOC(2003)6

ANNEX A: OECD TASK FORCE RECOMMENDATIONS 
DSTI/DOC(2003)6

\section{A1: SOFTWARE INVESTMENT IN THE SNA AND BUSINESS ACCOUNTS ${ }^{15}$}

\section{A.1.1 What is investment? (gross fixed capital formation)}

A.1.1.1 Before considering the treatment of software in the SNA and in business accounts, it is instructive to begin by reviewing how investment in the general sense is defined in the SNA93, and importantly the features that distinguish investment from intermediate consumption. This section illustrates that it is not always clear where the dividing line is between the two and that the decision on what is investment and intermediate consumption can often be based on relatively subjective factors, and that this can give rise to significant measurement differences across countries. This is true for all products and not just software; however, given its intangible nature and other special characteristics (e.g. "ownership" rules), software measurement is more sensitive to any ambiguities concerning the definition of investment.

\section{A.1.1.2 Paragraph 10.26 of the SNA defines gross fixed capital formation (GFCF) as:}

The gross fixed capital formation of an institutional unit or sector is measured largely by the value of its acquisitions less disposals of new or existing fixed assets. Disposals do not include consumption of fixed capital. Fixed assets consist of tangible or intangible assets that have come into existence as outputs from processes of production and that are themselves used repeatedly or continuously in other processes of production over periods of time of more than one year.

However, four caveats need to be added this definition:

\section{Small tools rule}

\section{A.1.1.3 Paragraph 6.158 of the SNA states that:}

Expenditures on durable producer goods which are small, inexpensive and used to perform relatively simple operations may be treated as intermediate consumption when such expenditures are made regularly and are very small compared with expenditures on machinery and equipment. Examples of such goods are hand tools such as saws, spades, knives, axes, hammers, screwdrivers, spanners and so on. However, in countries where such tools account for a significant part of the stock of producers' durable goods, they may be treated as fixed assets.

\section{Maintenance and repairs}

A.1.1.4 For maintenance and repairs, the SNA defines ordinary, regular, maintenance and repairs as intermediate consumption, and major renovations, taken at any point in time not dictated by the condition of the asset, that increase the performance or expected service life of the asset as investment.

15. See also the OECD Task Force report at http://www.oecd.org/doc/M00034000/M00034026.doc 
A.1.1.5 It is worth noting here that, under this definition, Y2K expenditure should be strictly treated as intermediate consumption, since remedial action was needed before a certain date. However there is some ambiguity. For example, one might consider any maintenance work that is not ordinary as being investment. Although the SNA further defines ordinary maintenance to include any costs that cannot be avoided if the fixed assets are to continue to be used.

A.1.1.6 That said, the ambiguity, as far as Y2K expenditure is concerned, may not have proven to be too demanding. Returns from the questionnaire suggest that, in practice, institutions carried out repairs that went beyond merely correcting for Y2K, often replacing systems altogether, and so actual expenditure related to Y2K was probably investment. Either way, the point is that it is not always clear how to define investment where maintenance and repairs are concerned, and this is arguably truer for software than it is conventional tangible assets. This is a point we will return to later.

A.1.1.7 This point is not lost on the SNA and it is explicitly referred to in paragraph 1.54:

In practice it is not easy to draw the line between ordinary repairs and major improvements, although the system provides certain guidelines for this purpose. Some analysts, however, consider that the distinction between ordinary repairs and maintenance and major improvements and additions is neither operational nor defensible and would favour a more "gross" method of recording in which all such activities are treated as gross fixed capital formation.

\section{Financial leases and operating leases}

A.1.1.8 The third point concerns the method of payment. The SNA distinguishes between operating leases that have more than one-year duration and financial leases. Financial leasing is viewed as a method of financing the purchase of capital equipment, where the intention is to transfer all risks and rewards of ownership to the lessee and so, in the accounts, finance leases are treated as if the underlying asset was purchased outright by the user. In practice it will not always be possible to determine when a lease arrangement should be considered a financing lease or an operating lease. This depends to a large extent on the expected working life of the asset and lease, and whether any special terms and condition apply.

\section{Rights to reproduce intangible assets}

A.1.1.9 The final point of particular relevance to software concerns reproduction rights. This issue has caused difficulties for many national accountants. Some have argued that the acquisition of rights to reproduce (for longer than one year) should be treated as investment on the grounds that (some) businesses view them in this way. This subject is described in more detail later. However, the SNA is explicit in how these activities should be treated. SNA 6.158 states that:

The owner (of the original) may also license other producers to make use of the original in production. The latter may produce and sell copies, or use copies in other ways; for example, for film or music performances. In these cases, the owner is treated as providing services to the licensees that are recorded as part of their intermediate consumption. The payments made by the licenses may be described in various ways, such as fees, commissions or royalties, but however they are described they are treated as payments for services rendered by the owner. The use of the asset is then recorded as consumption of fixed capital in the production of services by the owner. These services are valued by the fees, commissions, royalties, etc. received from the licensee. (My emphasis on intermediate consumption.) 


\section{A.1.2 Business accounting}

A.1.2.1 Section 1.2 described the definition given for software in the SNA broadly outlining what expenditure should be capitalised. What follows is an exposition of business accounting in theory and in practice, in order to determine differences, if any, between the SNA and business accounting approaches, and what this implies for software estimation in the national accounts.

\section{Theory}

A.1.2.2 Even before the introduction of SNA93, business accountants recognised that software whether purchased or produced in-house had asset characteristics. Thus, business accountants were presented with much the same challenges as those faced by national accountants - how to value and define software assets. This is still a relatively new development and so, the world over, accounting standard's bodies are currently attempting to bring these standards closer together. In summary, business accounting rules recommend that software copies purchased for own-use; originals, purchased or developed on own-account for reproduction; and other own-account software developed for own-use should be capitalised. A more detailed description of the US position is described in the box below. Further information can be found in Chapter 4 of the OECD final report.

\section{Box 1. The US approach, GAAP (generally accepted accounting principles), accounting for software intangibles}

Financial Accounting Standards Board Statement No. 86 was the first statement to address a standard method for accounting for software. Although this statement did not cover software developed in-house for internal use, clear guidance was given for software to be sold or leased (including "originals" produced for reproduction). This related to the capitalisation of software costs broken down by the different stages in the software development cycle and is described as:

... During the research and development stage all costs are to be expensed. At the point in time that the software becomes technologically feasible for use, the costs should be capitalised and treated as a product master copy with subsequent costs capitalised as an intangible asset. Amortisation of capitalised computer software costs begins when the product is marketed. Amortisation should be either based on the revenue method or a straightline method over the useful life.

Unlike the SNA, however, FASB86 allowed software produced for internal use to be expensed. In response to a request by the SEC, the FASB subsequently issued SOB 98-1 Accounting for the Costs of Computer Software Developed or Obtained for Internal Use. This statement (effective from 15 December 1998) stated that the costs of software developed or purchased for internal use should also be capitalised. But that the costs in the final stage of implementation/operation, such as training and maintenance, are to be expensed, and so brought US business accounting procedures into line with those recommended in the SNA. The situation regarding business accounting recommendations in other countries is largely consistent with the US position.

\section{Practice}

A.1.2.3 However, business accounts rarely record the value of own-account software at all. Business accounting rules generally recommend that own-account software should be capitalised after "technical feasibility" can be established. In practice, companies adopt a very prudent interpretation of when this occurs. Indeed in the case of most software-producing companies, e.g. Microsoft, own-account originals are not valued at all. Equally the accounting rules governing purchased software tend to be ambiguous, meaning that different companies use different interpretations, making complicating cross country comparisons but also making affecting national estimates based on demand-based surveys. It is largely for these reasons, (the lack of a watertight, common, and easily understood definition of software), that most National Statistical Offices use supply-based methods. 


\section{A2: INVESTMENT OR INTERMEDIATE CONSUMPTION}

\section{A.2.1 Software transactions - investment or intermediate}

A.2.1.1 This section tries to define software transactions. In the main, it follows the arguments presented in the OECD final report, however, it introduces some extra points in some sections (clarifying issues not readily understood by some national accountants concerning some aspects of the report), as well as completely new sections that consider alternative approaches to the OECD recommendations; raised in the OECD National Accounts October 2002 meeting. It looks at flows of software from a consumption perspective and recommends how these transactions should be treated in the national accounts. This is done by considering not only what is considered to be conceptually best but also what is achievable from a measurement perspective, particularly with regards to achieving international comparability, whilst all the time recognising the importance of maintaining consistency, wherever possible, with business accounting concepts and the needs of economic statistics users.

A.2.1.2 Two particular descriptions are given to software to help illustrate how software might be considered in this context. These are "licenses-to-reproduce" and "licenses-to-use". Neither description necessarily refers to a license in a strict national accounts sense; rather, they are used to describe payments by software publishers to software producers for a right to reproduce and sell a software original, (licenseto-reproduce), and payments from users of software reproductions in acquiring software copies or the right to use a software copy (license-to-use).

A.2.1.3 The section is broken down into eight parts: originals, licenses-to-reproduce, software bundles, licenses-to-use, double counting, royalty payments, maintenance payments, and databases. Based on the arguments presented in this section, Annex B shows concordance tables linking product classifications to transactions, differentiating between transactions that should be capitalised and those that should not, together with a revised, more comprehensive, definition of software, consistent with the rules set out below.

\section{A.2.2 Originals}

\section{Own-account software}

A.2.2.1 Businesses can acquire software by purchasing off-the-shelf prerecorded software, for example, MS Excel, by contracting specially developed (customised) software, or, by developing software in-house. The latter is referred to as own-account software. The capital services provided by own-account software are, in theory, no different from those provided by purchased software, and so, the case for capitalising purchased software needs to be extended to software produced on own-account.

A.2.2.2 Own-account software can be developed solely for the purpose of in-house use, for example a firm of architects may develop its own computer aided design (CAD) software, as an aid to producing building plans. This production may start from scratch, by generating the software directly from machine 
code say, or more commonly, by using readily available software and adding significant modifications, even if the original software is itself CAD software. The value of the own-account production should reflect the extra value-added generated by the architect firm, in other words the market value of the newly created software.

A.2.2.3 Alternatively, and more significantly, own-account software can be developed in order to produce a software "original" used to produce software reproductions for subsequent sale, for example Microsoft producing the software original "MS Excel". Or own-account software originals can be produced such that reproductions are embedded directly onto hardware, for example software reproduced on mobile phones and digital cameras.

A.2.2.4 In all cases, the view of the Task Force is that own-account software should be capitalised, or recorded as work-in-progress, destined for investment, (measurement of own-account production is dealt with in section A.3.3 below). Some countries questioned whether own-account originals produced for reproduction should be capitalised at all; the view of the Task Force is that they should be. The creation of an original is clearly part of a process of production, and it satisfies the SNA definition of economic assets, as long it provides economic benefits beyond one year, which is nearly always the case. The question largely arises from the belief that by capitalising an original and reproductions, total software is double counted. This is not the view of the Task Force, which considers "originals" and "copies" as distinct products, drawing on the analogy that an "original" is a machine that produces software copies. In any case the creation of the "original" occurs before sales of reproductions take place, and so its value must be recorded at its time of production. The double counting issue is discussed in more detail later.

\section{A.2.3 Licenses-to-reproduce}

A.2.3.1 A license-to-reproduce is defined here as any payment by a business to the owner of a software "original" that permits the purchaser to reproduce copies of the original. The payment can be in the form of a royalty, license etc. The SNA (Paragraph 6.146) states that payments for licenses-to-reproduce should be treated as intermediate consumption. These payments can be described in various ways, fees, commissions, royalties but they are always in respect of services provided by the owner (of the original). The owner then records the use of the "original" as consumption of fixed capital in the production of services.

A.2.3.2 However some businesses consider such a payment, where it covers a right to reproduce for longer than one year, as the acquisition of an asset, which contradicts the SNA position. Two alternative treatments, presented below, can be considered for licenses of longer than one-year duration but both were considered unsatisfactory by the Task Force, for national accounts' purposes, even after overlooking the fact that they were not consistent with the SNA.

\section{Treatment of licenses-to-reproduce as intangible non-produced assets}

A.2.3.3 In this treatment licenses-to-reproduce are considered as being intangible non-produced assets. In the SNA accounting framework this means that, when a license is issued, a transfer is made between the "original" and the new intangible non-produced asset (made in "other changes in volume of assets" account) where the value of the "original" is reduced by the value of the license. The subsequent transaction of the intangible non-produced asset is recorded in the capital account.

A.2.3.4 Two conceptual problems arise that invalidate this approach when a comparison is made between this proposal and the way transactions are recorded when the owner of the "original" manufactures copies itself: 
1. The total stock of fixed assets in the economy is lower.

2. The intangible non-produced asset is now assumed to be a production factor but as there is no consumption of fixed capital on intangible non-produced assets, net value added is higher.

\section{2. (Part) sale of a pre-existing asset}

A.2.3.5 This proposal considers the license-to-reproduce as a part sale of the "original" and reflects the position of some companies, which consider the license as an (often transferable) asset.

A.2.3.6 Three reasons led to this approach being ruled out by the Software Task Force:

1. A sale of a license-to-reproduce will not result in an increase in output or value added of the "original" owner. If reproduction is considered to have negligible (zero) input costs it would create significantly different value-added and output estimates between companies that carried out reproduction in-house and those that sold reproduction rights (i.e. asked another company to carry out the reproduction).

2. The license does not adequately satisfy the "ownership" criteria. The software producer always owns the "original" not the licensee.

3. Measuring these flows consistently will also prove very difficult. In practice estimating the value of an "original" is estimated using an input approach, using relatively prudent assumptions. Transfer costs aside, the transfer of one asset (or part of) from one party to another has a net zero impact on GDP and investment (unless the asset is exported/imported). However, this could mean that the "owner" of the original end ups with negative capital stock (as the "original" is likely to be valued, in practice, below its true market value). Unless, that is, a revaluation item is also recorded, when the license-to-reproduce is sold, which although complete in an accounting sense, is less so in an economic sense.

\section{A.2.4 Bundled/embedded software}

A.2.4.1 Bundling/embedding of software occurs when software copies are purchased or produced with the explicit intent of on-selling as part of, or within, another product. This transaction is not that different from the merchanting of goods purchased by the wholesale and retail industries (or any trade activity). For these two industries, purchases of goods for on-selling (not used up in the production process) are not recorded as intermediate consumption or investment. Only the margin activity related to the sale of each good is recorded as output, and the goods are considered to have been delivered from the producer to the consumer (facilitated by the trade industry).

A.2.4.2 For supply-use tables this poses some complications, since software purchased by a computer trader (for bundling) is mainly recorded when subsequently resold, in final demand, as consumption of office machinery, and not software. This means that output by the software (reproducer) is recorded as output of office machinery, and not software. However not all sales of bundled software are recorded in this way. For example, a computer manufacturer may purchase license-to-reproduce software that is directly embedded into office machinery. In these circumstances the license-to-reproduce will be recorded as intermediate consumption and the computer manufacturer records within output, the output of office machinery inclusive of the value of reproduced software. In this way a trader can also record intermediate consumption of software if it has purchased licenses-to-reproduce, yet as well as output of trade margin, it will record gross-output of office machinery, equivalent in value to the reproduced software. 
A.2.4.3 In this way it is clear that bundled/embedded software can be created in one of two ways. The first is when copies are purchased from a software producer and subsequently bundled and sold on to another consumer. The second occurs when a license-to-reproduce has been acquired and the (value of the) copied software is embedded in another product. In either case expenditure should be recorded as intermediate consumption.

\section{A.2.5 Licenses-to-use}

A.2.5.1 A license-to-use is defined here as being distinct from a license-to-reproduce. It should be interpreted uniquely as a payment for a right to use a software reproduction or (multiple copies) whereas a license-to-reproduce (see above) is considered as being a payment for the right to make copies; (payments can be made via royalties, commissions, fees, or a straightforward purchase of the software reproduction).

A.2.5.2 The view of the Task Force is that software copies purchased outright for own use, above a certain threshold (and not for bundling), should always be viewed as final demand, and for businesses, investment if they are used in production for more than one year. This treatment is consistent with the SNA and any real economic meaning given to investment but the difficulty lies in implementation of this principle in practice, since software copies are rarely sold without some conditions attached. Commonly, these definitions specify that ownership resides with the "original" owner, or that payments are made in the form of regular license payments to use the software. One might interpret these conditions to mean that the software producer owns the reproduction as well as the "original". However, there are good reasons to consider software licenses-to-use as being assets owned by the users, as long as usual rules of assets apply. These are listed below:

- Software purchased in association with a license that permits use is analogous to a tangible machine that provides capital services for more than one accounting period, and, so following this argument, like a tangible machine, if the software reproduction is used for more than one year it too should be recorded as an asset.

- Software purchased as a bundle (that is pre-installed with office machinery) is treated as investment (and was in SNA68 too). Treating (the same) software purchased separately as intermediate consumption but software purchased as a bundle as investment is inconsistent; affecting comparisons of investment across countries and time. For example, if software licenses-to-use are treated as intermediate consumption, a country that sold all software as bundles would have higher (total) investment than a country identical in every way except that software is purchased separately.

- Strict ownership is not a necessary condition to determine whether expenditure is investment. One example of this is long-term operating leases, which for many goods/services are equivalent to finance leases (see above). Because of the relatively short shelf life of software, any license-touse for a period of time approaching this, begins to attain "finance-lease" characteristics.

- The licensee has significant ownership characteristics. Namely that as soon as the licensee cancels the license the product (license/software copy) no longer exists. In effect the user destroys the software. This is a particularly strong characteristic of ownership.

- Where there is an intention to use the software for more than a year, treating the software as intermediate consumption is equivalent to saying that the licensee is renting an asset. This means that the licensee is renting the "original" or that the licensee rents a copy of the original. The former case is inconsistent, since the original should provide the same service whether the service 
is embodied/bundled within office and other machinery or if the service is purchased directly. But recording the payments as intermediate consumption means that embedded/bundled services are capitalised whereas directly purchased services are not. For the latter case to be consistent, in an accounting sense, the software provider will have to record an increase in its own assets, (software reproductions for rent) which, for national accounts users, is unhelpful. Ignoring the fact that output of the software producer would include production of the original, production of the copies, and production of rental services. It is unlikely, even under the most generous interpretations, that software producers or national accounts' users would consider these copies the assets of the software producers.

A.2.5.3 The strength of these arguments varies depending on the nature of the "license". Four specific examples of license payment are considered below.

\section{Simple purchase}

A.2.5.4 When a copy is purchased with a single (up-front) payment, all five arguments apply. The copy provides capital services to the user for the duration of its lifetime, the user owns the copy in the normal sense of the term (the software company cannot for example repossess the copy), and so it is clear that this transaction should be recorded as a purchase of an asset if other national accounts' asset rules are satisfied (one year and small tools rule).

\section{Annual payments}

A.2.5.5 Two specific cases are considered:

(I) Sequence of annual payments (an initial payment followed by smaller "maintenance" updates)

A.2.5.6 These transactions should be interpreted as purchases of software copies in the first year and purchases of updates (improvements to the first version) in subsequent years. Making an initial payment for acquisition of the software, followed by a series of smaller "maintenance license" payments in subsequent years, is little different in practice from making one up-front payment for the software reproduction, and so the treatment should be, in practice, the same, that is, that all payments should be recorded as investment, as and when they occur (as long as normal national accounts rules concerning investment apply).

\section{(II) Sequences of regular (equal) annual payments}

A.2.5.7 One particular and important type of transaction is when payments for a license-to-use are made annually in order to extend the use of the software. This type of license (and payment) is not unusual (for example SAS). For tangible products the national accounts' treatment with respect to licenses such as these is fairly clear. If the license-to-use includes a legal obligation to provide the asset for all (or nearly all) of the expected lifetime of the asset ownership is considered to be transferred to the leaseholder (using the normal accounting rules relating to financial leasing, since under these circumstances an operating lease should be treated as a financial lease). Where this is no legal obligation to provide the asset for all (or nearly all) of the expected lifetime of the asset, the payments would normally be recorded as intermediate consumption by the leaseholder. 
DSTI/DOC(2003)6

\section{(II)(a) Regular (equal) annual payments with obligation to provide software throughout lifetime}

A.2.5.8 Where there is an obligation to provide software throughout its expected working life (and for more than one year) the full value of the software reproduction should be capitalised in the first year of the acquisition of the software, with annual license payments corresponding to interest payments thereafter, following using usual national accounts rules for financial leases. The OECD Task Force recognised that this would be difficult to measure in practice and so concluded that it would be easier and acceptable to capitalise the annual license payments as and when they occur, see also A.2.5.14 below.

\section{(II) (b) Regular (equal) annual payments with no obligation to provide software throughout lifetime}

A.2.5.9 Following the rules for tangible products described in A.2.5.7 above, payments for software acquired via licenses-to-use that contain no legal requirement to provide software throughout the expected lifetime of the software should be recorded as intermediate consumption. However, there is one complication with this treatment. For tangible products, when a good is rented a corresponding underlying asset exists. By extension, if the software in these circumstances lasts for longer than one year, and is rented for an undetermined period, it must exist as an asset in the accounts of the software provider (the renter). To be fully consistent, the value of the software reproduction has to be capitalised at the time of creation (when the license is first issued) and should be valued as the discounted value of expected future income (all license payments expected from the software).

A.2.5.10 Recording the copies in this way is not particularly helpful. An alternative is to consider licenses of one year only as being equivalent to services provided by the "original", and so no (reproduced) asset is recorded in the accounts of the software provider, only the "original". One immediate consequence (and problem) with this approach is that it implies that the level of investment in the economy depends on the mode of payment. Or, that the same "original" has a different valuation depending on the mode of payment. But this is not the only problem with this approach. Consider, for example, what happens when a company purchases software "services" provided in a disc. The software provider delivers the disc for one year after which the leaseholder must return the disc, unless the company wishes to renew the license. If the company renews the license it is difficult to maintain that the services provided are not "rental" services, since the same disc has provided the services in both years, and so the disc should be recorded as an asset in the accounts of the software provider.

A.2.5.11 It seems fair to say, therefore, that the factor that determines if an asset is recorded in the accounts of the software provider or not is whether the leaseholder renews the annual contract beyond one year. As far as software is concerned, this is more likely than not to be the case, since companies rarely acquire software to use it for less than one year. The fact that payments have to be made every year largely reflects contractual obligations and not the intent of the company. In this respect it can be argued that companies nearly always intend to use software for more than one year. The acquisition of software by a company involves significant other start-up costs such as training, and it is unlikely that companies will undertake, or be willing to undertake, these additional costs every year.

A.2.5.12 And so, where licenses-to-use do not have an obligation to provide software throughout its expected lifetime, an asset should (almost always) be recorded in the accounts of the software provider. As stated above this is not a desirable outcome. Firstly, recording the assets within the capital stock of the software provider makes little intuitive sense (even if conceptually complete), particularly when one considers that, in practice, most companies are likely to purchase (and renew) licenses throughout the software's expected working life (and from here the parallels with financial leasing can again be brought to bear). Secondly, estimating the value of the assets being rented will be very difficult. The full cost of the asset has to be valued and estimated in the year of production and if that were not difficult enough it is not 
readily possible to determine when the reproductions were made, only when the payments for use are recorded and received. This is not a very practical approach. Instead, it makes more sense to record investment by the "renter", as long as there is an intention to rent for more than one year, and this is what the OECD Task Force recommended.

A.2.5.13 By extension, one can conclude that all licenses-to-use (irrespective of the duration) should be recorded as investment, as long as companies can establish an intention to use these products (by renewing licenses) for more than one year (which is usually the case).

A.2.5.14 This means that some software purchased for less than one year may be investment and some intermediate consumption. What distinguishes one type from another is the notion of "intent", and the interpretation of this may differ across countries or even time, but this is not a problem peculiarly specific to software. If licenses to use (for any duration) are treated as investment, one needs to impute the full value of the software in the first year with license payments treated as interest payments in accordance with accounting rules on financial leases. The data requirements to do this properly are severe, however, and the OECD Task Force concluded that it would be preferable to record investment as being equal to actual payments made in that year, without any adjustments, although this has implications for capital consumption. ${ }^{16}$

\section{Licenses-to-use intended for use of less than one year}

A.2.5.15 Licenses intended for use for less than one year should be treated as intermediate consumption. At present the value of these types of licenses is not significant but this may change if software is made available through the Internet, for example, on a "pay per use" basis. Licenses-to-use not intended for use of more than one year, do not lead to the creation of an asset, neither in the capital stock of the provider nor the user. From the outset it can be established that the software will not last for more than one year as it is the intention of the user to "destroy" it beforehand, and so under these circumstances cannot be considered an asset.

\section{Rentals}

A.2.5.16 The preceding discussions apply as much to software rentals (a rare occurrence, and so of limited practical significance) as they do licenses-to-use (indeed rentals should merely be viewed as one of the payment mechanisms for licenses-to-use). And, so, where there is intent to rent for more than one year, payments should be recorded as investment.

\section{A.2.6 Double counting}

A.2.6.1 The rationale presented above, in effect, means that most expenditure on software reproductions, whatever the license terms, will be capitalised. Intuitively this makes sense, as software is considered by its users to have asset characteristics and indeed its take-up has been used by many to explain productivity growth over the last decade. The alternative, recording expenditure on software reproductions as intermediate consumption despite the capital services it provides, would be at odds with these commonly held positions. That said, some national accountants have expressed some concern that in capitalising software reproductions total investment is in effect recorded twice: once for the "original" and once for the copies. As such, two alternative recording mechanisms for software reproductions have been put forward.

16. This means that payments for less than or equal to one year will have to be completely amortised within the year. 
The first treats the sale of a reproduction as being a part sale of the "original". The second considers the payment for the license-to-use as being equivalent to a payment for access to the original, in effect meaning that software reproductions do not exist. Both options are reviewed below but first we review what the SNA says on originals and reproduction of originals.

\section{Machines and originals}

\section{A.2.6.2 SNA 6.143 states:}

"The production of books, recordings, films, software, tapes, disks, etc. is a two-stage process of which the first stage is the production of the original and the second stage the production and use of copies of the original. The output of the first stage is the original itself over which legal or de facto ownership can be established by copyright, patent or secrecy. The value of the original depends on the actual or expected receipts from the sale or use of copies at the second stage, which have to cover the costs of the original as well as costs incurred at the second stage."

And SNA 10.92 states that:

"Computer software that an enterprise expects to use in production for more than one year is treated as an intangible fixed asset. Such software may be purchased on the market or produced for own use. Acquisition of such software are therefore treated as gross capital formation."

A.2.6.3 From the above it is clear that intangibles are produced as part of a two-stage production process: the first stage produces the original, and in the second stage the original is used to produce copies. Further, if the copies are expected to be in use for more than one year, payments should be recorded as investment. Seen in this way a simple analogy can be made that to allay the concerns raised by the "double counting" theory. That analogy is to consider the software "original" as being a factory or machine that is capable of producing software copies, in much the same way that most other tangible assets are produced, for example a motor car and a car production plant. In this case both the factory and the car (if purchased by a business) are capitalised. The fact that depreciation of the factory is incurred in producing the motor car does not mean that it is not also capitalised: indeed this is one of the reasons why the national accounts' measure of investment is "gross", as in gross fixed capital formation.

A.2.6.4 For software, the confusion stems from the facts that the cost of actual reproduction itself is seen as being negligible and that the copy has the same physical attributes as the "original". However, if software reproductions required tangible and significant intermediate inputs, such as a motor car and, for example, if software copies were only available on (expensive and resource-intensive) compact discs, the treatment of software copies as investment would be largely incontrovertible. In this regard it is important to note that the SNA does not specify what is and is not investment on the basis of the production process or indeed the size of intermediate costs. In any case, although the intermediate costs of physical reproduction may be relatively small, other intermediate costs are not. For example, marketing and documentation costs, which are also intermediate inputs into software reproduction. The two alternative proposals are considered below.

\section{Part sale of the "original"}

A.2.6.5 This idea proposes that software copies, when purchased, are netted off the value of the "original" so that the sale of a copy makes no impact on global investment levels, it merely redistributes investment from the owner of the "original" to the user of the copy. It works largely, although not exclusively, on the assumption that reproduction costs are negligible. If they were not, then for practical 


\section{DSTI/DOC(2003)6}

purposes, it would be literally impossible to record the necessary flows in a meaningful way as it would be necessary to estimate for each copy the (usually unknown) costs of reproduction. In any case, if reproduction costs were significant the argument that double-counting occurs would be largely void. There are two reasons why this proposal does not work (even if it were possible to estimate reproduction costs).

A.2.6.6 The first relates to measurement, and follows the reasoning described in paragraph A.2.3.6 above. In short, difficulties in estimating the value of the "original" will be exacerbated, and could result in negative capital stock for the owners of the "original", as is likely as "originals" are valued prudently. The second reason is because if licenses-to-use are treated as parts of originals, licenses-to-reproduce also need to be, and this is inconsistent with the SNA. This is best illustrated by means of a theoretical example, which assumes that licenses-to-reproduce are not recorded as purchases of parts-of-the-original (but as intermediate payments for services, the SNA treatment) and that licenses-to-use are recorded as purchases of parts-of-the-original.

Company A owns a software original of value $X$ produced in year $t$. It reproduces copies worth $X_{t+1}$ in year $t+1$, and sells these to Company $C$. Following the formulation above, total investment in year $t$ is $X$ and in year $t+1,0$. Assuming no intermediate costs by Company $A$ in producing the original or copies but costs $Y$ for reproduction, Value-added of company $A$ in year $t$ is $X$ and in $t+1$ is $Y$. Capital stock in $A$ (assuming no depreciation) is $X-X_{t+1}+Y$ and in $C$ it is $X_{t+1}-Y$.

Now consider the case where Company A sells reproduction rights to Company B, worth $X t+1-Y$, which then sells copies to Company $C$, all in year $t+1$. Again in Year t, company A has value-added of $X$. But in year 2 it has value-added of $X t+1-Y$, (sale of a right to reproduce). In addition Company $B$ has paid Xt+1-Y for a license-to-reproduce but only output $Y$, since it essentially only facilitates redistribution of reproductions from Company A to Company C. So, if Xt+1>2Y (which is likely, if reproduction costs are negligible) Company $B$ has negative value-added. For the economic accounts this distorts the value-added of Company B, rendering it meaningless, in effect Company $B$ is paying for the pleasure of acting as a conduit. Equally and perversely it means that Company A has lower value-added and output if it produces reproductions itself compared to the case where another company (B) pays to do so. The only way this could be squared was if the license-to-reproduce was also recorded as an asset but this is inconsistent with the SNA treatment for licenses-to-reproduce.

A.2.6.7 Interestingly if $2 Y$ was greater than $X_{t+1}$ the rationale for recording reproductions as "parts of the original" is greatly reduced, since the distinction between a copy and the original is much clearer. In much the same way that tangible assets are distinct from the factory that produces them, for example a carfactory and a car, both of which are capitalised.

\section{Payment for access rights}

A.2.6.8 This proposal is based on the idea that software reproductions do not in their strictest sense exist. Instead, what exists is a medium that allows the software user to gain access to the software "original". In this way it is argued that every asset can be considered as part tangible and part intangible. The intangible part is the original concept; for software, the "original". The tangible part is the access device that allows the concept to be used. Using this formulation it is argued that software users rent the intangible "original" by paying to gain access through an access-device, and that the cost of this access device for most software is zero (or negligible when software is accessed via a disk).

A.2.6.9 This means that any user of software, no matter how long the period of use, never acquires an asset. They merely rent the "original". This is a novel way to look at the issue of intangibles but it does raise some challenging questions. In particular, the proposal can be extended to all assets, since most assets 
embody an intangible and tangible component. A book for example has a tangible part, the paper, and an intangible part, the story, of which there is one original. In this way the proposal is to identify and disentangle the tangible and intangible components of the book, or any economic asset.

A.2.6.10 Assume for convenience that a book could be capitalised, as long as it satisfied the basic economic asset criteria. Using this notion of "access rights", it would be necessary to record only the tangible component as an asset (the paper or access device) in the national accounts, and to record payment for accessing the story as "rental" of the "original". This, in practice, is what is being proposed for software, except that, for software, because the access device has little, if any, value, all payments for software are rentals.

\section{Embedded, bundled software would need to be separately estimated}

A.2.6.11 The implications of this proposal are far reaching. It would mean that any software sold via a bundle with a PC, say, would have to be unbundled for the purposes of the national accounts and be recorded as rental of an "original". At present, of course, the cost of the PC and the software are capitalised together. This is unlikely to be achieved easily by national accountants, and certainly not in a way that ameliorates international consistency. But the proposal goes beyond just bundles, since, for completeness, it also requires any software embedded in a product to be separately identified as a payment for access to the "original", and because software is present in literally every manufactured good from refrigerators to railway engines, it would be necessary to remove the software component from each of these and record it separately as a rental.

\section{In practice, measuring these costs would be very difficult}

A.2.6.12 Statistically it is literally impossible to achieve this in any meaningful way and for this reason alone the proposal, although interesting as a concept, must be viewed as a non-starter in practice.

A.2.6.13 Moreover, it is questionable that the costs of providing an access device for off-the-shelf software are negligible. In practice, companies spend considerable sums marketing and distributing their software, together with the documentation that is often supplied. Are these costs part of the "original" or part of the access device? So, determining the split between what is the tangible and intangible component of software, in particular the intangible component related to the original, is not clear cut. Furthermore, as tangible goods increasingly embody "intangible" production costs, design, embedded software, etc., the distinction between the two becomes increasingly blurred, and the difficulty involved in estimation becomes larger.

A.2.6.14 One might argue that the proposal could be adopted for just off-the-shelf software, and not software that is bundled or embedded. But this could seriously affect international comparisons of software, longitudinal analyses, KLEMS based productivity measures, and be conceptually incomplete.

\section{License conditions state that ownership resides with the owner of the "original"}

A.2.6.15 Part of the reasoning for this alternative method relates to ownership, in particular, the fact that license conditions state explicitly that the ownership resides with the owner of the "original". This has been recognised in formulating the OECD position (see section A.2.5 above).

A.2.6.16 In this respect, a comparison with tangible goods is interesting. It is mainly because the productive capacity of a software copy is equivalent to an original that manufacturers attach conditions of 
sale and use that they would not normally attach, visibly, to tangible goods. But for tangible goods, these conditions exist nonetheless. A purchaser of a truck, for example, would not be allowed to reproduce the truck, despite the fact that, on purchase, these conditions are not explicitly spelt out, since other more conventional legal devices protect the manufacturer's rights: intellectual property, copyright, patents, etc. In this way, and for the national accounts, we interpret the licensing conditions on software to mean that further reproductions are not allowed but that the users are owners, and this is the interpretation that most users have.

\section{Originals prudently recorded}

A.2.6.17 A point often overlooked when the double counting argument is made is that, in practice, the valuation of software originals has always been, and is likely to continue to be, prudent. Meaning that in practice, double counting (as understood in this context) does not occur, even if conceptually a case could be made to substantiate it.

A.2.6.18 In theory the value of an "original" should equal the current value of expected future revenue, or, in other words, the value of revenue generated by sales of copies (directly or indirectly, and excluding reproduction costs). So, if the value of all copies, excluding reproduction costs, were $\mathrm{X}$, so too in theory should be the value of the original. However in practice the "original" is rarely valued at X, indeed it is usually only valued, prudently, as a small proportion of $\mathrm{X}$, and this is likely to continue to be the case.

A.2.6.19 Looked at another way, if we accept that "originals" and copies should be capitalised, it turns out that, rather than double-count software, national accountants in practice under-record it. On its own this point renders both of the alternative solutions presented above impractical.

\section{A.2.7 Royalties}

A.2.7.1 Payments for licenses-to-reproduce and licenses-to-use (and even rentals) are often described as royalties (sometimes commissions and fees); in fact the (license) descriptions given above are rarely used. It is because "royalties", in these circumstances, cover a diverse range of transactions with specific characteristics that has led to the specification of transactions given above - licenses-to-reproduce and licenses-to-use. In this sense "royalties" should be considered a generic term referring to payments linked to re-produced software with some license conditions attached, or a payment for permission to reproduce software.

\section{A.2.8 Maintenance}

A.2.8.1 What makes the consideration of maintenance and repairs particularly problematic for software is that it is difficult to describe a software repair that is not an addition to an existing software system. For example there are few equivalents to the replacement of a part, say, in conventional plant and machinery. A repair to software systems involves a change in the configuration or code of any programme, but not the replacement of a part, or repairing something that no longer works. In this way software repairs may largely be seen as improvements. Repairing "faults" introduced by bugs say, may be one example where an analogy can be made with replacements of defective parts. But other repairs or modifications, for example modifying software to provide protection from a bug, can be seen as analogous to giving a car a paint job to protect it from unusually (unanticipated) wet weather. On the other hand, it might be viewed as being analogous to fitting a new all-weather engine. 
A.2.8.2 Maintenance on the other hand suffers less from these problems. Conventional maintenance (distinct from repairs), such as systems checking, does not change the characteristics of the software and so is clearly intermediate consumption. There are however some complications in practice, particularly when existing software is adapted to operate on a new operating system. In this example it is not clear whether new software (and so GFCF) has been created, or, whether maintenance has been carried out on preexisting software to allow it to continue to be used (and so intermediate consumption).

A.2.8.3 That said, evidence from businesses suggests that, in practice, businesses can differentiate between maintenance and repair expenditure that is intermediate consumption and that that investment.

A.2.8.4 It is possible to arrive at a satisfactory outcome for maintenance if it is adequately defined, however. And it can be defined as: All changes made to software that do not add a new feature to the software and that are not made voluntarily by the owner but are imposed by a change in the environment of the software are to be considered as maintenance; and the costs as intermediate consumption.

A.2.8.5 In this respect, $\mathrm{Y} 2 \mathrm{~K}$ modifications strictly limited to make a programme $\mathrm{Y} 2 \mathrm{~K}$ compatible are intermediate consumption, and changes in a programme imposed by a necessary adaptation to a new operating system are also intermediate consumption. On the contrary, a software editing company that develops another version of the same programme adapted to another operating environment is contributing to investment. In this case, the "change" is not imposed but voluntary, (and should not be considered as maintenance and repair activity). For example, the adaptation by a software editing company of a programme originally made for Windows to an Apple environment is GFCF.

\section{A.2.9 Databases}

\section{The SNA definition}

A.2.9.1 In recognising that databases produced economic benefits SNA93 recommended that they should be recorded as economic assets.

SNA 10.2 and 10.3 define economic assets as:

10.2 The assets recorded in the balance sheets of the System are economic assets. These are defined as entities:

(a) Over which ownership rights are enforced by institutional units, individually or collectively.

(b) From which their owners may derive economic benefits by holding them, or using them, over a period of time.

10.3 Every economic asset must function as a store of value that depends upon the amounts of the economic benefits that its owner can derive by holding it or using it. However, this value does not usually remain constant as the benefits remaining often diminish with the passage of time. Different kinds of benefits may be derived from different kinds of assets, as follows:

(a) Some benefits are derived by using assets such as buildings or machinery in production.

(b) Some benefits consist of property incomes: for example, interest, dividends, rents, etc., received by the owners of financial assets and land. 
(c) Finally, assets act as stores of value that may be realised by disposing of them or terminating them. While some assets may be held until the benefits derivable from them are exhausted, others may be disposed of before that point in order to realise the capitalised values of the benefits still remaining. Some assets may be held purely as stores of values (precious metals or stones, etc.) without any other benefits being derived from them.

A.2.9.2 It is clear that many databases satisfy these criteria. For example databases held by market research companies that sell data, or indeed directory inquiry databases owned by telecommunications companies. In the same way the definition can be extended to other databases for example Statistical Office databases or databases developed purely for in-house administrative purposes, (see proposal 2 below).

A.2.9.3 What is not so clear however is what a database actually is? Particularly when one considers the ambiguity of the qualification "large" used in the SNA; since the SNA gives no further guidance regarding the monetary value or measurable size specified for "large". Indeed the qualification means that the definition of economic assets for databases differs from any other economic asset (where only the small tools rule applies).

A.2.9.4 From a practical perspective it is difficult to define large in a meaningful and non-arbitrary way and, more importantly, from a conceptual perspective it means that the meaning of "economic assets" for databases differs from other economic assets. Arguably the qualification "large" should be dropped from the SNA, which would make measurement easier (at least within a conceptual framework) but what matters more is defining what a database is, in a national accounts sense.

\section{Definition of databases}

A.2.9.5 The dictionary definition of database can be summarily described as follows:

A collection of data arranged for ease and speed of search and retrieval.

A.2.9.6 A more detailed (technical) definition, available from "Webopedia" (a Web-based dictionary for computer terms) is:

A collection of information organised in such a way that a computer program can quickly select desired pieces of data - an electronic filing system. Traditional databases are organised by fields, records, and files. A field is a single piece of information; a record is one complete set of fields; and a file is a collection of records. For example, a telephone book is analogous to a file. It contains a list of records, each of which consists of three fields: name, address, and telephone number. An alternative concept in database design is known as Hypertext. In a Hypertext database, any object, whether it be a piece of text, a picture, or a film, can be linked to any other object. Hypertext databases are particularly useful for organising large amounts of disparate information, but they are not designed for numerical analysis. To access information from a database, you need a database management system (DBMS). This is a collection of programs that enables you to enter, organise, and select data in a database.

A.2.9.7 "TechWeb", another on-line technical dictionary, defines databases as:

A set of related files that is created and managed by a database management system (DBMS). Today, DBMSs can manage any form of data including text, images, sound and video. Database and file 
structures are always determined by the software. As far as the hardware is concerned, it's all bits and bytes.

A.2.9.8 In a literal sense, therefore, the definition of a database seems pretty clear, since all three definitions are in broad agreement. A database consists of two parts: the database management system (the supporting software) and the data files stored on the DBMS. But how does this translate into the National Accounts? Ignoring "large" for now, this would mean that literally any information stored on an electronic format and held in a structured (electronic) repository should be capitalised, as long as it satisfied other asset rules (e.g. the one-year-rule). But from a philosophical perspective should electronic data really be considered as having asset characteristics?

\section{Electronic data}

A.2.9.9 Electronic data refers to data available in an electronic format. However, it is not clear how electronic data can be defined such that it is delineated from a DBMS. For example, if significant electronic data from one database are reproduced for use in Excel spreadsheets and sold to another company, is the (Excel) data itself an asset, even though it is not supported by a conventional DBMS? After all, Excel also has characteristics (in this case) that are similar to a DBMS. Following this argument through suggests that all (significant) electronic data should be capitalised. Indeed some electronic data also satisfies SNA 10.2 and 10.3.

A.2.9.10 If one considers data as being a form of knowledge, this marks a significant precedent for the SNA - the capitalisation of knowledge. By extension one might argue why data available on (some) books or data and (preposterously) facts stored in the mind are not also capitalised.

A.2.9.11 What is it that makes electronic data so special? Electronic data is knowledge converted into a format that facilitates ease of access (usually within a conventional DBMS). In this way it becomes easier to see why books are not capitalised but an electronic version of the same book on a DBMS might be (since multiple users have access). But if it is the "improvement in access" that is the defining characteristic of databases as assets, investment in databases can be "artificially" increased in the National Accounts, since the same data can be bought, reproduced, and sold many times. On the other hand, some data is clearly more accessible in hard copy than it is in electronic format, and so the argument for capitalisation might be extended to (some) books too. Indeed, some books last a great deal longer than electronic data, which can become obsolete and inaccessible due to changing technology and even ageing of the storage devices (discs, tapes).

A.2.9.12 However, there are some distinguishing features of electronic data, for example a long time series of electronic data can be readily analysed in a way that hard-copy data cannot (unless it is first converted into an electronic format). By extension we can conclude that (significant) data manually input, or electronically copied, onto an electronic format has asset characteristics. But what does this mean for the National Accounts, since not everything that has asset characteristics is necessarily recorded as such.

A.2.9.13 Moreover, in practice, it is very difficult to consistently determine the expected life of electronic data, since, in theory, one can argue that all electronic data last for longer than one year, and so are intended for use for longer than one year. On the other hand, just because the data exist for more than one year does not mean that they have a productive capacity that lasts longer than one year. For example, a database of national accounts statistics for the first quarter of 2002 would have become practically worthless once statistics for the second quarter were available.

A.2.9.14 In addition, to be conceptually coherent, all databases should be capitalised, including administrative personnel databases for example, whether the databases are for own use (and non-market 
services) or for market services. And the practical implications of measuring own-account database production for all of these databases are severe. Businesses will be very reluctant to capitalise them and for National Accountants it will be literally impossible to do so in a meaningful way. Unlike own-account software production, which can be sensibly limited to "software professionals" the same cannot be said of electronic data creators - (which in practice many of us are). This report for instance could in theory be thought of as investment. It is electronic, and it will be accessible for some time to come but is it really investment? Indeed, is there such a thing as a professional database compiler?

A.2.9.15 Crucially, one might ask at what point electronic data develops asset characteristics. Is it when hard-copy data is originally converted into an electronic format? Or, is it when the electronic data has been transferred onto a DBMS? The former can be discounted for several reasons, particularly practical (and is considered in more detail in Option 1 below). But if it is the latter, as the SNA appears to imply, this is odd, since the DBMS does not change the electronic data in any way, it only provides a facility to access the data, which, when not held within a DBMS, is not investment. For example a drilling machine facilitates access to underground oil, and is investment, but this does not make the oil GFCF in the national accounts sense, so why should "data" be investment when it is accessed by a DBMS?

A.2.9.16 All of the factors considered above play a part in the proposals that follow, each of which describes in detail an approach considered by the OECD Task Force in its deliberations. In each case it is important to recognise that a database will always have some part capitalised, that is the software (DBMS). It is the extra value added provided by the data, separate from the software, which needs to be considered.

\section{Option (1)}

A.2.9.17 That all acquisitions of electronic data with an expected working life of more than one year should be recorded as investment. Where electronic data can be purchased or produced on own-account.

Problems

- It is difficult to consistently determine the expected life of electronic data, since, in theory, one can argue that all electronic data lasts for longer than one year, and so is intended for use for longer than one year.

- All databases are capitalised, including administrative personnel databases.

- Measurement of own-account production of electronic data is practicably impossible. One might advocate that own-account database creation should be ignored. However capitalising purchased (electronic) data but not own-account production of electronic data would be inconsistent, and compromise cross-country comparisons and longitudinal analyses.

Option (2)

A.2.9.18 This proposal is based on the belief that the SNA initially set out to record the databases of data (base) providers only, that is databases of companies engaged in (market) data services related to the database. The principal is that these companies can be readily identified and as such, own-account database production of these companies (only) should be recorded as investment. Sales of data to companies (who may have identical but non-market databases) to other companies are recorded as intermediate consumption. 
Problems

- In practice, it is impossible to define these companies in an economically consistent manner. For example, some companies/institutions are not primarily engaged in providing data services, but use (internal) databases as inputs into their production process. Under this proposal these databases would not be recorded as assets. In addition it is not obvious how databases owned by companies/institutions that sell some, but not all, data from the database should be recorded. This is important because many statistical institutions for example sell some data. Furthermore any database produced internally by a company for own-use that is subsequently sold to a data provider (to provide market services back to the original owner) would be an asset in the books of a data-provider, although no prior (own-account) production would have been recorded. In the same way any data-company that provides data services exclusively to one company that subsequently purchases the database would be recorded as asset destruction (intermediate consumption) and not asset transfer. In any case it is difficult to see why databases owned by statistical organisations or used primarily for internal administrative purposes should not be considered as assets, if databases that provide market services are so considered, since they both provide the same services. To reinforce this point, no distinction is made in the National Accounts (or this report) for own-account software originals produced for internal use or for market-services.

Option (3)

A.2.9.19 That databases are capitalised only when all exclusive proprietary rights are sold as transfers of existing assets, in other words sales/purchases of non-financial (produced) assets. Transactions should be recorded as "other volume changes in non-financial assets n.e.c. (K9)". The value of the software included in the database should be recorded as a normal transfer of pre-existing (software) assets, and the remainder as $(K 9)$.

A.2.9.20 In practice, when large databases are sold from one company to another it is often because the purchasing company has seen an opportunity to use the database in ways not previously anticipated by the original owner. In this way the value of the database increases (or decreases) depending on the purchaser, in other words the intended use of the database. This is analogous to increases (and decreases) resulting from conversions of dwellings to commercial use, which are recorded as (K9) in the SNA.

A.2.9.21 The benefit of this proposal is that it largely circumvents the contentious issue of data capitalisation, providing a way forward that is not technically demanding.

Problems

- Assets are transferred but no (own-account) production of the data in the database is ever recorded.

One might contend however that:

- Large databases are developed slowly over time, and so (annual) own-account production is not likely to be significant.

- The value of databases can increase or decrease depending on its intended use. In other words, the value changes at point of sale not related to any production, and so this change in value 
DSTI/DOC(2003)6

(which is usually far in excess of production costs) should be recorded as "other changes in volume”.

- Equally, in practice such transactions are unlikely to be recorded as sales of existing assets. More probably they will be recorded as "takeovers" by companies.

\section{Conclusion}

A.2.9.22 The capitalisation of databases raises a number of philosophical questions. Chief amongst these is the capitalisation of data, which can be copied many times, and, over which, ownership rights rarely apply. The deliberations of the OECD Task Force pointed to prudence in considering this matter; namely that data should not be capitalised, mainly on practical grounds but also on conceptual grounds that merit further discussion. The OECD Task Force on Intangibles may provide some further insight into this. 
DSTI/DOC(2003)6

\section{A.3: ESTIMATING SOFTWARE INVESTMENT IN PRACTICE - THE SUPPLY METHOD}

\section{A.3.1 Context}

A.3.1.1 Traditional methods (demand-based) for measuring investment have not, so far, proven successful in estimating software. In the short to medium term it is difficult to see any serious improvement in this situation since business surveys will need to be redesigned and businesses given significant guidance. This will require some commitment from countries and there will inevitably be some cost involved that, for some, might prove too expensive or burdensome. As such there may be a long implementation period before demand-based methods can be considered as reliable.

A.3.1.2 Operationally, even with a more definitive meaning of software, difficulties in estimation and statistical harmonisation are likely to persist because differences in tax regimes across countries will remain, and one cannot rule out the fact that businesses will continue to be influenced by the tax regime in operation. Furthermore it is hard to envisage valuations of own-account produced software being harmonised in a systematic way within countries, let alone internationally. As such, supply-based methods will continue to be necessary and used. It is important to stress, however, that in principle demand-based methods are preferable to supply-based methods and that countries should be encouraged to continue to develop and improve surveys so that they overcome the "harmonisation" problems that exist in today's surveys.

A.3.1.3 A harmonisation of the treatment of concepts, as set-out in section A.2, will improve international comparability between those countries that use supply methods but other reasons for divergence are likely to persist unless clear guidelines are specified for supply-based methods. This section describes the methodology needed to achieve harmonisation in this area. The approach is necessarily different for purchased software and own-account production and each is presented separately.

\section{A.3.2 Purchased software}

A.3.2.1 The underlying principle for estimating investment in software using as supply approach is simple. Investment in software is calculated as:

$$
\text { Total domestic supply }+ \text { imports }
$$

minus

Exports, households' expenditure, software purchased for bundling, subcontracted software, and software included within own-account production valuations.

(All at purchaser's prices. Pre-packaged software (licenses-to-use) and customised software only, assuming an intention to use that software for more than one year and no small tools purchases). 


\section{DSTI/DOC(2003)6}

A.3.2.2 In practice, however, estimation is a little more complicated for a number of reasons. (1) It is not always possible to differentiate between pre-packaged and customised software and other computer services within total supply of computer services. (2) As demonstrated earlier import data does not always separately identify software. And (3) software purchased for bundling and subcontracted software expenditure are usually not separately identifiable.

A.3.2.3 However, these problems are not irresolvable. (1) Although information for pre-packaged software and customised software may not be directly observable information is collected using standard product classifications (such as the European CPA classification) that broadly allow these categories of software to be identified - namely CPA 72.20.2, 72.20.32, 72.20.33. (Although this includes some software that does not satisfy asset requirements, for example payments for licenses-to-reproduce, which are included within CPA72.2, and so need to be excluded; see Annex A.) (2) In practice, many countries are able to estimate software contained within imports, for example Canada includes other "software", reflecting software royalties, within its supply estimates. (3) It is possible to estimate bundled software, at least in a harmonised way across countries. The OECD final report recommends that $50 \%$ of all expenditure on pre-packaged software by the computer hardware industry should be assumed to be payments for bundles. In theory a similar adjustment could also be applied to the publishing and wholesale/retail industries; although anecdotal evidence suggests that the values involved are not significant.

A.3.2.4 The following table provides a practical and simple guide to software estimation using the practical working assumptions set out above, providing links to US SIC and European CPA classification systems. (For further information see Chapter 5 of the OECD final report).

Table A1. Estimating purchased software, the supply approach

\begin{tabular}{|c|c|}
\hline $\begin{array}{l}\text { Value of sales of capitalisable software services (SIC } 73.71+\text { SIC } 73.72 ; \\
\text { CPA } 72.20 .2+72.20 .32+72.20 .33+72.20 .34) \text {, including royalties and license } \\
\text { fees, including games software }\end{array}$ & A \\
\hline Inclusion of imports (including royalties and license fees and games) & $\mathrm{B}$ \\
\hline Inclusion of trade margins and taxes on domestic supply and imports & $\mathrm{C}$ \\
\hline $\begin{array}{l}\text { Exclusion of software embedded by hardware industry (50\% of purchases of } \\
\text { pre-packaged software by hardware industry), treated as intermediate } \\
\text { consumption }\end{array}$ & $\mathrm{D}$ \\
\hline Exclusion of sub-contracting flows between "software companies" & $\mathrm{E}$ \\
\hline $\begin{array}{l}\text { Exclusion of household consumption in games and other pre-packaged } \\
\text { software }\end{array}$ & $\mathrm{F}$ \\
\hline Exclusion of exports (including royalties and license fees and games) & $\mathrm{G}$ \\
\hline Exclusion of maintenance (CPA $72.20 .34,10-15 \%$ of SIC 73.71) & $\mathrm{H}$ \\
\hline Total GFCF in purchased software & $A+B+C-D-E-F-G-H$ \\
\hline
\end{tabular}

"Capitalisable" software - supplied software that satisfies the asset requirements set out in section 3 and in Annex A.

\section{A.3.3 Own-account software}

A.3.3.1 Because there is no observable market price for own-account produced software, it is necessary to estimate the value of the software using an input-based method. Indeed SNA93 recommends that ownaccount production of software is valued at its estimated basic price or at its costs of production if it is not possible to estimate the basic price (10.92). 
A.3.3.2 Therefore own-account software can be defined and estimated as the following:

\author{
Total number of employees working on own-account software production \\ * \\ Average remuneration \\ $*$ \\ Proportion of time spent on own-account development \\ $+$ \\ Other intermediate costs used in own-account production \\ $+$ \\ Notional operating surplus related to own-account production
}

A.3.3.3 For harmonisation and measurement purposes, it is sensible to restrict the definition of an employee that can produce own-account software to software professionals only, who, in any case, produce most own-account software. Some countries collect this information by specifying an employment category for this occupation. Where this information is not separately collected, and for international comparability countries are encouraged to use estimates from the International Standard Classification of Occupations 88 (ISCO) category 213 , computer professionals.

A.3.3.4 Average remuneration, or compensation of employees, should include wages and salaries, social contributions (including imputed social contributions) and any related compensations-in-kind.

A.3.3.5 Not all of the time of each employee within ISCO 213 will be spent on own-account production. Some of their time will be spent working on software to be sold directly to an external customer (customised software that is, and not production of "originals" for reproduction, which are own-account production), or, in conducting other in-house, but not own-account, activities such as maintenance work. Therefore any time not spent on own-account production has to be excluded. The United States adopts a $50 \%$ deduction rule. The $50 \%$ share originates from a 20-year old study on the share of software development and maintenance costs in 487 business organisations reported in a study by Barry Boehm. ${ }^{17}$ Other countries apply the same percentage, e.g. Canada, France and Italy.

A.3.3.6 There are a number of ways of estimating non-labour intermediate costs but perhaps the most common assumes that the intermediate input to compensation of employees ratio in the computer services industry is representative of the ratio for computer professionals more generally, irrespective of the industry they happen to work in. Some care should be taken when calculating this ratio to ensure that any software (incorrectly) included within the intermediate consumption part of the ratio has not already been accounted (corrected) for as investment when using the supply approach.

A.3.3.7 Estimating the operating surplus can be done in a similar manner; that is, by assuming that the ratio of operating surplus to compensation of employees in the computer services industry is representative of that for all computer professionals working on own-account production.

A.3.3.8 Because intermediate costs and parts of compensation of employees include costs incurred at the R\&D development stages, some national accountants have expressed concern that this approach, in effect, results in the capitalisation of $\mathrm{R} \& \mathrm{D}$, which the SNA says should not be capitalised. This is not considered to be the case here. $R \& D$ costs are only used in this context to estimate the basic price of the own-account software. They are not considered as capitalisable in their own right. In the same way that other intermediate costs, e.g. intermediate expenditure on electricity for lighting and heating say, used by computer professionals whilst working on own-account production, will also be included in the basic price of the own-account software, and are not considered on their own as capitalisable expenditure.

17. Barry W. Boehm, Software Engineering Economics (Englewood, NJ: Prentice-Hall, 1981): 533-35, 548-50. 


\section{ANNEX B: CONCORDANCE TABLES}

B.1 This annex presents concordance tables between standard product (and industry) classification tables and under what circumstances transactions should be recorded as investment or intermediate consumption. All transactions are seen from a user's perspective. This includes any software produced via own-account, where the "user" consumes his/her own production. Seen in this way, the concordance tables refer explicitly to use and not production. As a matter of fact, seen from the user's perspective, the simplest of all criteria is the following: if the user is the final consumer of software, it is investment; if the user is not the final consumer, it is intermediate consumption.

B.2 Software produced by own-account methods can occur in any of the "investment" classification categories listed below but in practice it will be difficult to identify this and so, in practice, software produced on own-account should only be recorded under "originals", or "customised software". For simplicity the concordance tables presented below for own-account production make no attempt to allocate production to a specific (detailed) industrial classification within computer services. For convenience the small tools rule is not explicitly referred to in the tables that follow but should be considered to apply in all cases. Transactions only relate to businesses and government.

\section{CPA concordance table}

B.3 What follows are concordance tables based on the European product classification system (CPA). Where the treatment is non-contentious (and evident) no further explanation is given.

B.4 The first table considers purchases of software and the second own-account production. That is where software is intended for final-use by the purchaser and not intended for further processing, nor for bundling/embedding (including outsourced purchases) in a subsequent sale, nor where the software is purchased as part of own-account production. 
DSTI/DOC(2003)6

Table B1. Purchases of software

\begin{tabular}{|c|c|c|}
\hline CPA code & Product description & $\begin{array}{c}\text { Intermediate or } \\
\text { investment }\end{array}$ \\
\hline 72.1 & Hardware consultancy services. ${ }^{18}$ & IC \\
\hline 72.2 & Software supply services and other related services. & \\
\hline 72.20 .1 & $\begin{array}{l}\text { Recorded data bearing media etc. } \\
\text { This category originates from the Harmonised System and is intended to cover the exports and } \\
\text { imports of software "goods", i.e. the physical carriers of software such as diskettes and CD-ROMs } \\
\text { as they are registered by customs' authorities. These carriers can contain any kind of information, } \\
\text { such as data, databases, software, pictures, etc. It is recommended that any items recorded within } \\
\text { this category are transferred to the appropriate CPA category below. }\end{array}$ & Ignore \\
\hline \multirow[t]{6}{*}{72.20 .2} & $\begin{array}{l}\text { Programming services of packaged software products. } \\
\text { Our understanding is that this category includes purchases of originals (including games) and } \\
\text { reproduced software (on-the-shelf software, whatever the media). This includes licenses-to-use } \\
\text { and licenses-to-reproduce and rentals. }\end{array}$ & \\
\hline & Original software - (purchases of pre-existing software originals). & GFCF \\
\hline & $\begin{array}{l}\text { Other reproduced purchased, rented, leased or licensed software expected to be used in } \\
\text { production for more than one year. Including payments for "multiple-copy" licenses. (Payment can } \\
\text { include, royalties, commissions, fees etc.) }\end{array}$ & $\begin{array}{l}\text { GFCF excluding } \\
\text { games }^{19}\end{array}$ \\
\hline & $\begin{array}{l}\text { Other reproduced purchased, rented, leased or licensed software, expected to be used in } \\
\text { production for less than one year. } \\
\text { (Payment can include, royalties, commissions, fees etc.) }\end{array}$ & IC \\
\hline & $\begin{array}{l}\text { When purchased for bundling/embedding into products for subsequent sale (whether the products } \\
\text { are hardware, other equipment (chips on planes, cars, boats etc) or other software products or just } \\
\text { sold-on. }\end{array}$ & IC \\
\hline & Payments for licenses-to-reproduce software for subsequent sale. & IC \\
\hline 72.20 .3 & Software consultancy and other supply services. & \\
\hline 72.20 .31 & $\begin{array}{l}\text { Systems and technical consulting services. } \\
\text { (Includes advice and assistance on technical matters, equivalent to stage } 1 \text { of the production } \\
\text { process - see paragraph 1.2.2.1 above) }\end{array}$ & IC \\
\hline \multirow[t]{3}{*}{72.20 .32} & $\begin{array}{l}\text { Custom software development services. } \\
\text { (Includes development (analysis, design and programming) of software for, and to meet the } \\
\text { requirements of, a specific client (including self) and-modification of packaged software). }\end{array}$ & \\
\hline & $\begin{array}{l}\text { Software expected to be used in production for more than one year. } \\
\text { (Including embedding in an own-account "original") }\end{array}$ & GFCF \\
\hline & $\begin{array}{l}\text { Software expected to be used in production for less than one year. } \\
\text { (This includes "customised" software purchased to be sold-on to another user/client.) }\end{array}$ & IC \\
\hline \multirow[t]{3}{*}{72.20 .33} & $\begin{array}{l}\text { Systems analysis and programming services. } \\
\text { (Includes provision of systems analysts' and/or programmers' services on a per diem basis to } \\
\text { participate in one of the phases of the development of a system. The client supervises and retains } \\
\text { the right to their work.) }\end{array}$ & \\
\hline & $\begin{array}{l}\text { Software expected to be used in production for more than one year. } \\
\text { (For inclusion/embedding in an own-account "original" - the value of own-account production must } \\
\text { not include these costs.) } \\
\text { If the software is purchased by a final-user for inclusion in an own-account "original" the } \\
\text { expenditure may also be treated as intermediate consumption as long as its value is included in } \\
\text { own-account production. }\end{array}$ & GFCF \\
\hline & $\begin{array}{l}\text { Software expected to be used in production for less than one year. } \\
\text { (This includes "customised" software purchased to be sold-on to another user/client.) }\end{array}$ & IC \\
\hline 72.20 .34 & $\begin{array}{l}\text { Systems maintenance services. } \\
\text { (Includes provision of assistance to keep computer systems (software) in good working condition. } \\
\text { The maintenance may be corrective or preventive). }\end{array}$ & IC \\
\hline 72.20 .35 & Other professional computer-related services. & IC \\
\hline \multirow[t]{3}{*}{72.4} & Databases and database services. & \\
\hline & Where exclusive ownership rights are transferred. & GFCF \\
\hline & All other database services, including data sales etc. & IC \\
\hline 72.5 & Maintenance and repair services of office, accounting and computing machinery. & $\mathrm{IC}$ \\
\hline 72.6 & Other computer-related services. & $\mathrm{IC}$ \\
\hline
\end{tabular}

18. Category 72.1 in France includes sales that would normally be classified under 72.2.3. France should apply recommendations in 72.2.3 for a large part of its category 72.1. This example is specific to France but other countries may have similar problems, and so should convert their own estimates as necessary.

19. Unless purchased by games arcades, game rental companies, etc. 
DSTI/DOC(2003)6

B.5 The Table below describes the treatment of own-account production of software.

Table B2. Own-account production

\begin{tabular}{|l|l|c|}
\hline CPA Code & \multicolumn{1}{|c|}{ Product description } & $\begin{array}{c}\text { Intermediate or } \\
\text { investment }\end{array}$ \\
\hline 72 & $\begin{array}{l}\text { Own-account produced software. } \\
\text { In practice the following should be capitalised: } \\
\text { Compensation of staff and all internal overhead costs involved in the strict development } \\
\text { of in-house software. This includes the development of in-house originals destined for } \\
\text { reproduction. In other words, the internal costs of software editing companies incurred } \\
\text { in this production should also be capitalised. } \\
\text { Costs should only include those strictly related to the software itself. Costs related to the } \\
\text { first phase of the software (stage 1 above) or to the last phases (stages 7 and 8) should } \\
\text { be excluded. }\end{array}$ & GFCF \\
\hline
\end{tabular}

\section{US SIC concordance table}

B.6 Similar concordance tables are shown below (Tables B3 and B4) using the US SIC classification. ${ }^{20}$ NAICS codes and amounts of sales (in millions of US dollars for the United States for the year 97) have been added for information and clarification.

B.7 Creating a concordance for the US SIC based on the CPA table is, in most cases, relatively easy given the similarity in classification descriptions. However there is one area where there is some ambiguity: NAICS 541512 (SIC 7373 and part of SIC 7379), computer systems design services. The exact definition of this activity is the following: activity of establishments primarily engaged in planning and designing computer systems that integrate computer hardware, software, and communication technologies. The hardware and the software components of the system may be provided by this establishment or company as part of the integrated services or may be provided by third parties or vendors. These establishments often install the system and train and support users of the system.

B.8 There could be various interpretations of this activity. One interpretation is that it relates only to the integration of the various hardware components. In that case, costs linked to these services are not to be included in the value of the software asset in itself. However, another interpretation is that the software cannot function without these integration services. In that case, these costs should be included in the value of the software.

20. The SIC was used rather than the more recent NAICS because of its similarity with the NACE/CPA classification. SIC and NAICS are industry and not product classifications but used here as if they were a product classification. 
DSTI/DOC(2003)6

Table B3. Purchases of software

\begin{tabular}{|c|c|c|}
\hline $\begin{array}{l}\text { US SIC } \\
\text { Code }\end{array}$ & "Product" description & $\begin{array}{c}\text { Intermediate of } \\
\text { investment }\end{array}$ \\
\hline \multirow[t]{3}{*}{73.71} & $\begin{array}{l}\text { Computer programming services. } \\
\text { NAICS } 541511,38,300 \text { USD: Custom computer programming services: services of writing, } \\
\text { modifying, testing, and supporting software to meet the needs of a particular customer. This } \\
\text { category is similar to CPA } 72.20 .32 \text { Custom software development services and CPA } \\
72.20 .33 \text {. }\end{array}$ & \\
\hline & $\begin{array}{l}\text { Software expected to be used in production for more than one year. } \\
\text { (Including - embedding in an own-account "original"). } \\
\text { If the software is purchased by a final-user for inclusion in an own-account "original" the } \\
\text { expenditure may also be treated as intermediate consumption as long as its value is included } \\
\text { in own-account production }\end{array}$ & GFCF \\
\hline & $\begin{array}{l}\text { Software expected to be used in production for less than one year, including expenditure on } \\
\text { maintenance and repair (see section 1.6) and "customized" software purchased to be sold-on } \\
\text { to another user/client. }\end{array}$ & IC \\
\hline \multirow[t]{5}{*}{73.72} & $\begin{array}{l}\text { Software publishers. } \\
\text { NAICS } 5112,61,700 \text { USD: establishments in this industry produce and distribute software } \\
\text { (design, documentation, assisting in installation, provide support services to software } \\
\text { publishers). This category seems similar to CPA } 72.20 .2 \text { Programming services of packaged } \\
\text { software products. }\end{array}$ & \\
\hline & Original software - (purchases of pre-existing software originals; and originals). & GFCF \\
\hline & $\begin{array}{l}\text { Other reproduced purchased, rented, leased or licensed software expected to be used in } \\
\text { production for more than one year. (Payment can include, royalties, commissions, fees etc). }\end{array}$ & $\begin{array}{l}\text { GFCF excluding } \\
\text { games }\end{array}$ \\
\hline & $\begin{array}{l}\text { When purchased for bundling/embedding into products for subsequent sale (whether the } \\
\text { products are hardware, other equipment (chips on planes, cars, boats etc) or other software } \\
\text { products or just sold-on. }\end{array}$ & IC \\
\hline & $\begin{array}{l}\text { Other reproduced purchased, rented, leased or licensed software, expected to be used in } \\
\text { production for less than one year. (Payment can include, royalties, commissions, fees etc). }\end{array}$ & IC \\
\hline 73.73 & $\begin{array}{l}\text { Computer systems integrators and consultants. } \\
\text { "This category covers approx. 70\% of NAICS } 541512 \text { Computer systems design services, } \\
\text { (USD 51200, 70\% = USD 35,800). This industry comprises establishments engaged in } \\
\text { planning and designing computer systems that integrate computer hardware, software, and } \\
\text { communication technology". This category is related to CPA } 72.30 .31 \text { Systems and technical } \\
\text { consulting services. The definition of this category explicitly says that sales can include } \\
\text { hardware. If hardware is included, this should be classified as GFCF in hardware. If not, } \\
\text { under the point of view of this table which is to treat software services, these transactions } \\
\text { seem to relate to intermediate consumption, because these costs do not relate to the asset } \\
\text { software itself, but to its installation. }\end{array}$ & IC \\
\hline 73.74 & $\begin{array}{l}\text { Data processing services } \\
\text { NAICS } 5142,30,840 \text { USD. This is clearly intermediate consumption. }\end{array}$ & IC \\
\hline 73.75 & $\begin{array}{l}\text { On-line information systems } \\
\text { NAICS } 5114191,8,000 \text { USD }\end{array}$ & IC \\
\hline 73.76 & $\begin{array}{l}\text { Computer facilities management services. } \\
\text { NAICS } 541513,15,100 \text { USD: provision of on-site management and operation of clients } \\
\text { computer systems. }\end{array}$ & IC \\
\hline 73.77 & $\begin{array}{l}\text { Computer rental or leasing. } \\
\text { NAICS 532420, 5,700 USD: not related to software. }\end{array}$ & IC \\
\hline 73.78 & $\begin{array}{l}\text { Computer maintenance or repair. } \\
\text { NAICS } 811212,7,600 \text { USD: not related to software. }\end{array}$ & IC \\
\hline 73.79 & $\begin{array}{l}\text { Other computer services } \\
\text { This category contains NAICS } 334611 \text { Software reproducing (USD 1,300), 30\% of NAICS } \\
541512 \text { computer systems consultant (USD 51200, 30\% = USD 15,900), and NAICS } 541519 \\
\text { Other computer related services (USD 4400). Except for the small flow of NAICS } 334611 \text {, } \\
\text { these services seem to be classified as intermediate consumption (considering "computer } \\
\text { systems consultant", see classification of 73.73) }\end{array}$ & IC \\
\hline
\end{tabular}


DSTI/DOC(2003)6

Table B4. Own-account production

\begin{tabular}{|c|l|c|}
\hline US SIC Code & & $\begin{array}{c}\text { Intermediate or } \\
\text { Investment }\end{array}$ \\
\hline 73.7 & $\begin{array}{l}\text { Own-account produced software } \\
\text { In practice the following should be capitalised: } \\
\text { Compensation of staff and all internal overhead costs involved in the strict development } \\
\text { of in-house software. This includes the development of in-house originals destined for } \\
\text { reproduction. In other words, the internal costs of software editing companies incurred } \\
\text { in this production should also be capitalised. } \\
\text { Costs should only include those strictly related to the software itself. Costs related to the } \\
\text { first phase of the software (stage 1 above) or to the last phases (stages 7 and 8) should } \\
\text { be excluded. }\end{array}$ & GFCF \\
\hline
\end{tabular}


DSTI/DOC(2003)6

\section{ANNEX C: COMPREHENSIVE DEFINITION OF SOFTWARE}

The OECD/Eurostat Task Force agreed on the following form of words to fully define software:

Software consists of computer programmes, programme descriptions and supporting materials for both systems and applications software. Licenses-to-use or reproduce software are not separated from the underlying software, and are thus included in this category. Software covers the following sub-categories:

Original software: original software are machines used in the process of production of other products, and as such are considered as investment. Originals can be produced on own-account (they are then called "own-account original software") or can be bought ("purchased original software"). This includes games' originals. Originals cover two types:

Originals for reproduction: original software whose purpose is to be reproduced. They are generally the result of the production of software editing companies.

Other originals: software that can be used in the process of production of other products.

Reproduced software: reproductions of software are copies of original software. They include software giving users the rights, or license, to use, and software that gives the rights, or licenses, to reproduce:

\section{Licenses-to-use:}

They are mostly marketed, and thus called "packaged software" or "off-the-shelf software". In general they legally provide a license-to-use the software. This category includes reproduced software for final use and reproduced software for bundling in hardware, other equipment or other software. This category also covers "multiple copy" licenses-to-use and software "rented" for use, for which payments often take the form of "royalties". It excludes licenses that permit copies to be made for sale.

\section{Licenses-to-reproduce:}

Licenses-to-reproduce permit companies to make further software reproductions (licenses-to-use) for subsequent sale. These reproductions can be sold via licenses-to-use or as part of a bundle, whether the bundled software is included separately or embedded directly onto hardware. Often, licenses-to-reproduce are paid for using royalties.

Software must be used in production for more than a year and satisfy the small tools rule. The development of any "original" is own-account production for investment, and should be recorded as asset category AN1122. Games' software should be treated in the same way as conventional software, reflecting the similar production processes (and producers) for games' and conventional software. 